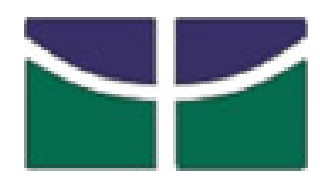

Universidade de Brasília

Centro de Excelência em Turismo

\title{
Aplicação do sistema de Análise de Perigos e Pontos \\ CRÍTICOS DE CONTROLE NO PROCESSAMENTO INDUSTRIAL DE MEL DE ABELHAS Apis mellifera
}

\author{
Aluno: Lilian Osachlo
}

Monografia apresentada ao Centro de Excelência em Turismo da Universidade de Brasília como requisito parcial para obtenção do certificado de Especialista em Qualidade em Alimentos.

Orientação : José Walter Dias

Brasília-DF, abril de 2004 
Universidade de Brasília

Centro de Excelência em Turismo

Curso de Especialização em Qualidade em Alimentos

\title{
Aplicação do sistema de Análise de Perigos e Pontos \\ CRÍTICOS DE CONTROLE NO PROCESSAMENTO INDUSTRIAL DE MEL DE ABELHAS Apis mellifera
}

\author{
Aluno: Lilian Osachlo. \\ Banca examinadora \\ José Walter Dias \\ Farmacêutico, especialista em Microbiologia Alimentar \\ Orientador \\ Wilma Maria Coelho Araújo \\ Doutora em Tecnologia de Alimentos \\ Membro da Banca
}

Brasília, DF, abril de 2004 
Lílian Osachlo

\section{Aplicação do sistema de Análise de Perigos e Pontos CRÍTICOS DE CONTROLE NO PROCESSAMENTO INDUSTRIAL DE MEL DE ABELHAS Apis mellifera}

Comissão Avaliadora

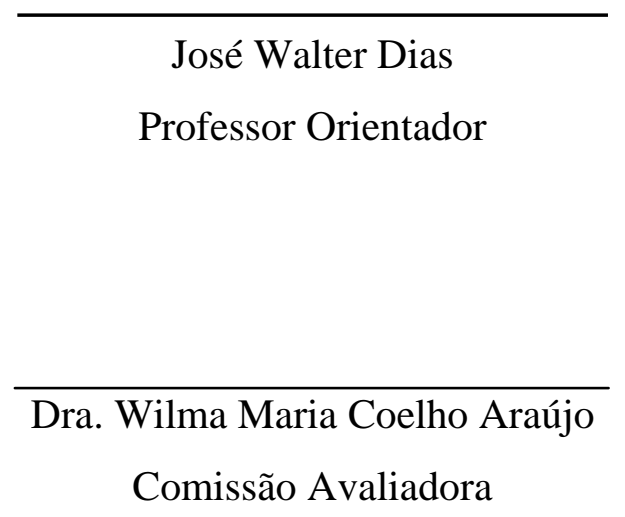




\section{RESUMO}

O mel é um produto de excelente valor nutritivo, que pode ter a qualidade comprometida devido à forma como é obtido e manipulado. Sendo o Brasil o décimo segundo produtor mundial de mel com grande potencial de crescimento, deve ajustar-se à preocupação mundial crescente com relação à segurança e qualidade dos alimentos. O sistema de Análise de Perigos e Pontos Críticos de Controle (APPCC) tem sido indicado como o método mais eficiente para garantir a qualidade e segurança alimentar. Assim sendo, o objetivo deste estudo foi aplicar o referido sistema ao processo de industrialização do mel de abelhas Apis mellifera. As etapas de recepção, descristalização e fechamento foram consideradas os pontos críticos de controle devido à possibilidade de contaminação por Clostridium botulinum. Além disso, a etapa de descristalização foi relacionada com a perda de qualidade do produto final. Limites críticos e medidas de controle como seleção de fornecedores, treinamento e educação dos manipuladores foram indicados como ferramentas para assegurar a qualidade do mel processado

Palavras-chave: mel; APPCC; qualidade; botulismo; segurança alimentar. 


\begin{abstract}
Honey is a product of excellent nutritious value. It might have its quality endangered due to how it is obtained and handled. Being the $12^{\text {th }}$ in the producer's rank - with great growth potential - Brazil must tune into the world's concern regarding food safety and quality. The System Hazard Analysis and Critical Control Point (HACCP) has been pointed out as the most efficient method to guarantee food quality and safety. Thus, the purpose of this essay is to apply the mentioned system to the bee honey (Apis mellifera) industrialization process. The phases of reception, decrystalization, and closing were considered to be critical control points, due to the possibility of Clostridium botulinum contamination. Besides, the decrystalization relates to the final product quality. Critical limits and control measures like suppliers selection and training/education of the food handler were indicated as tools to assure the processed honey quality.
\end{abstract}

Key words: honey; HACCP; quality; botulism; food safety. 


\section{SUMÁRIO}

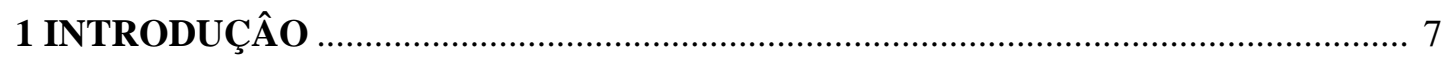

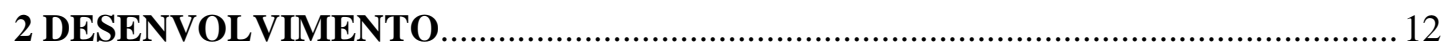

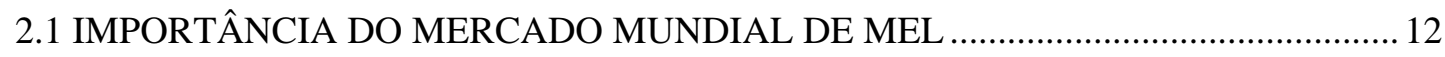

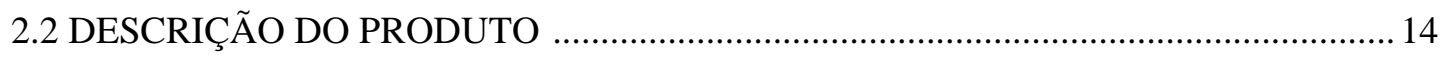

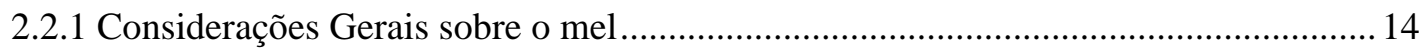

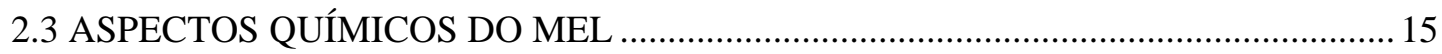

2.4 PROPRIEDADES FÍSICAS E FISICO-QUÍMICAS DO MEL ............................................ 16

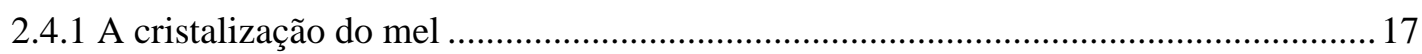

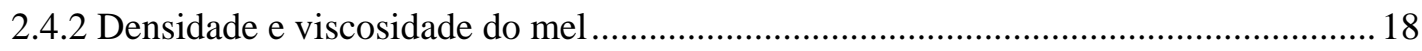

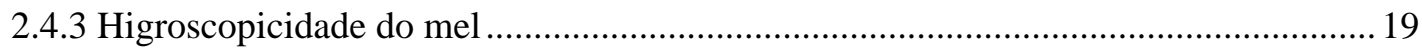

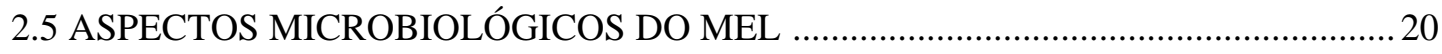

2.5.1 Leveduras e fermentação do mel ................................................................................20

2.5.2 Contaminação do mel e multiplicação microbiana......................................................... 22

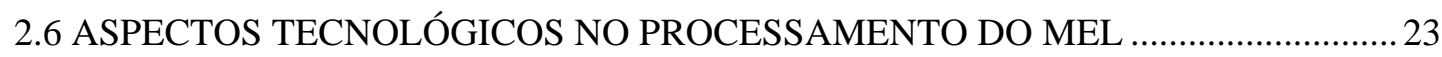

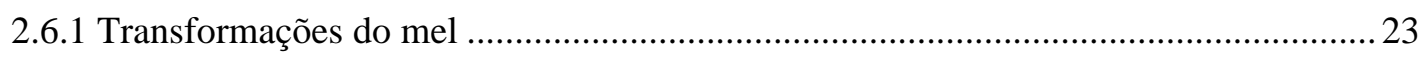

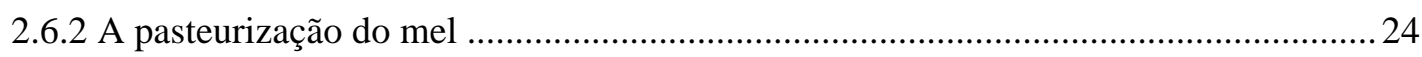

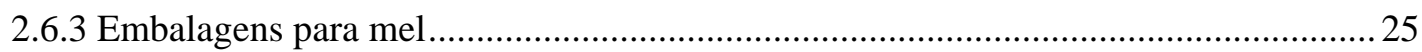

2.7 ASPECTOS SANITÁRIOS NO PROCESSAMENTO DE ALIMENTOS E

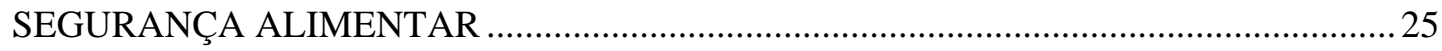

2.8 DOENÇAS TRANSMITIDAS POR ALIMENTOS (DTAs) ………………................... 26

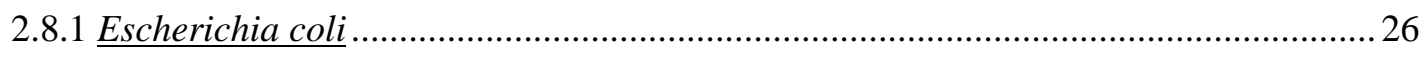

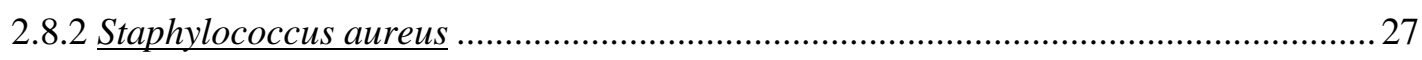

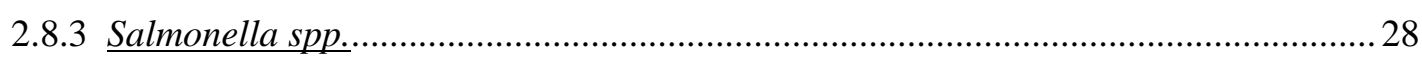

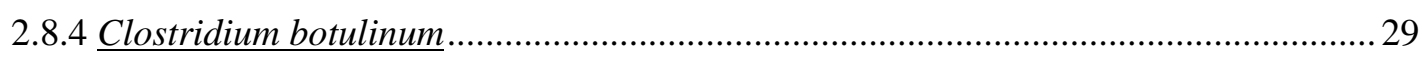

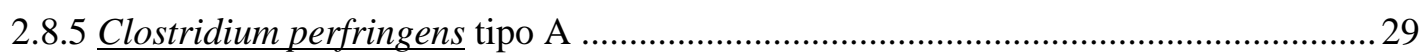

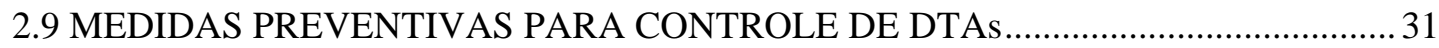

2.10 O SISTEMA DE ANÁLISE DE PERIGOS EPONTOS CRÍTICOS DE CONTROLE .... 34

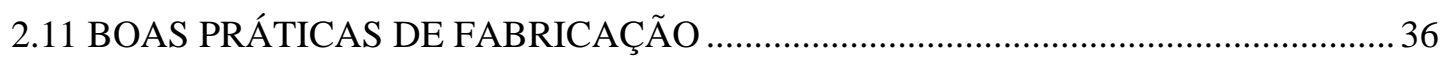

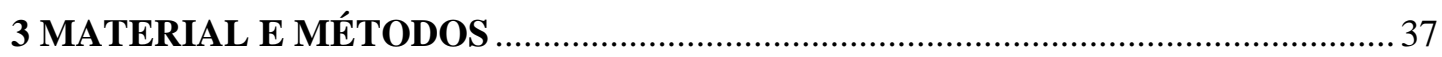

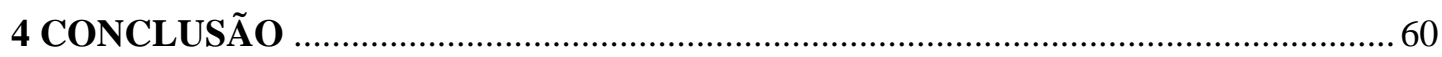

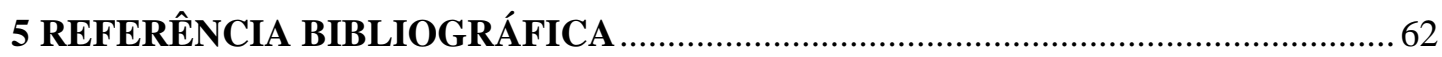

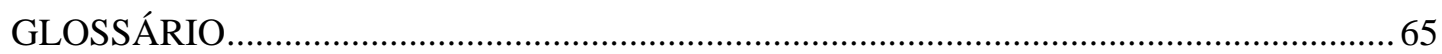




\section{LISTA DE TABELAS E FORMULÁRIOS}

Tabela 1 - Estimativas de surtos de doenças veiculadas por alimentos no estado do

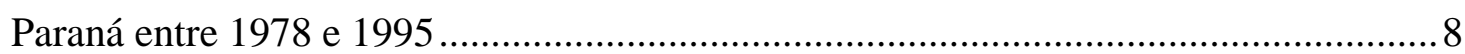

Tabela 2 - Produção mundial de mel no ano 2001 ........................................................ 12

Tabela 3 - Produção mundial de mel, por país,em toneladas, no ano de 2001 .............13

Tabela 4 - Importações e exportações brasileiras de mel natural no período de 1998 e 2001, expressas em toneladas ..... 13

Tabela 5 - Relação da possibilidade de fermentação em relação ao teor de umidade dos méis .22

Tabela 6 - Resumo dos parâmetros que influenciam no desenvolvimento de

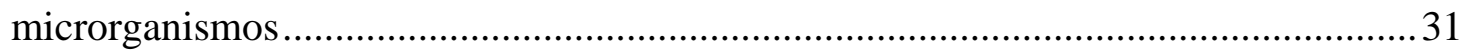

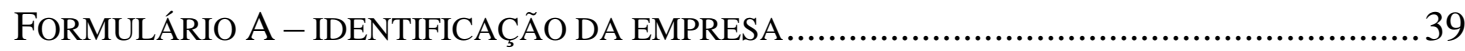

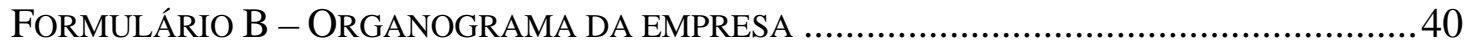

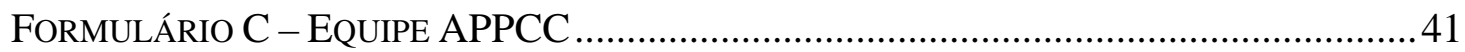

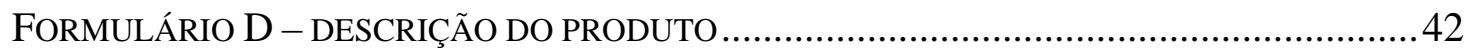

FORMULÁRIO E - COMPOSIÇÃO DO PRODUTO ......................................................... 43

FORMULÁRIO F - FLUXOGRAMA E DESCRIÇÃO DO PROCESSO........................................ 44

FORMULÁRIO G - IDENTIFICAÇÃO DOS PERIGOS - PERIGOS BIOLÓGICOS ..........................50

FORMULÁRIO H - IDENTIFICAÇÃO DOS PERIGOS - PERIGOS FÍSICOS.................................51

FORMULÁRIO I - IDENTIFICAÇÃO DOS PERIGOS - PERIGOS QUÍMICOS ...............................52

FORMULÁRIO J - QUADRO DE PERIGOS NÃO CONTROLADOS NO ESTABELECIMENTO.......53

FORMULÁRIO L - IDENTIFICAÇÃO DE MATÉRIA-PRIMA/ INGREDIENTE CRÍTICO ...............54

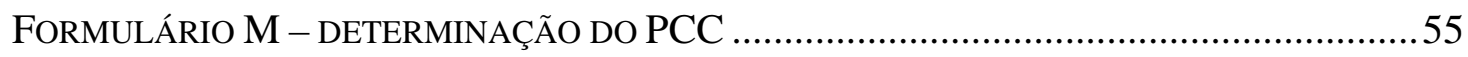

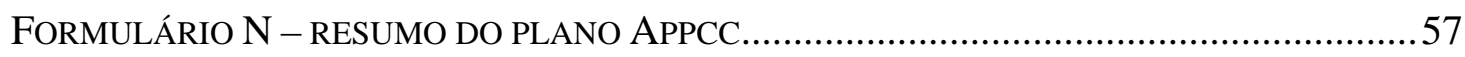




\section{INTRODUÇÃO}

O mel, alimento natural de alto valor nutricional na alimentação humana, "requer conhecimentos técnicos para manter suas características essenciais durante a comercialização”. E, para prolongar a sua vida-de-prateleira até o consumo final, é necessária a aplicação de algumas operações básicas de processamento, bem como de acondicionamento adequados (Faria,1983).

Nos últimos 20 anos, apesar das flutuações, houve um incremento na produção mundial de mel, atribuído ao aumento no número de colméias e à produtividade das colônias. Além disso, verificou-se ter ocorrido um crescimento mundial do consumo de mel, associado a uma mudança geral nos padrões de vida e também a maior interesse por produtos naturais e saudáveis (EMBRAPA, 2003).

Conforme Manual genérico de procedimentos para APPCC em indústrias de produtos de origem animal (BRASIL, 1998), mundialmente, verifica-se um rápido crescimento e aprimoramento de novos recursos e procedimentos para detectar agentes de natureza biológica, química e física causadores de enfermidades nos seres humanos e animais, veiculadas pelo consumo de alimentos. Oliveira; Gonçalves; Shinohara e Stamford (2003) afirmam que apesar desta evolução tecnológica para aprimorar as técnicas de conservação dos alimentos, estes são reconhecidamente o principal vetor das enfermidades entéricas agudas.

Além disso, conforme documento do Ministério da Agricultura e do Abastecimento (BRASIL, 1998), avolumam-se os desperdícios de alimentos e matérias-primas devido a processos deteriorantes de origem "microbiológica, infestação por pragas e processamento industrial ineficaz”, o que causa graves prejuízos financeiros à indústria de alimentos, à rede de distribuição e aos consumidores. Richards (2002) complementa que o consumo de alimentos contaminados é o principal problema de saúde pública, causando grave impacto econômico, conseqüente de faltas ao trabalho, sobrecarga nos sistemas de saúde com a ocupação de leitos hospitalares e gastos com medicamentos.

O mesmo autor também esclarece que os consumidores têm exigido "alimentos seguros", visto o crescente número de doenças transmitidas por alimentos, provocadas por consumo de alimentos contaminados. Afirma também, que as indústrias de alimentos cada 
vez mais concentram seus esforços na busca pela segurança alimentar e na logística para assegurar a qualidade de seus produtos, seja na produção, transporte, armazenamento, distribuição e consumo, pois isso é o fator primordial para sobrevivência das empresas no mercado.

É necessário esclarecer que os "alimentos seguros" não oferecem risco zero, diferentemente do que os consumidores consideram. A maioria dos pesquisadores concorda que risco zero é inexeqüível, devido à "quantidade de produtos alimentícios disponíveis, à complexidade da cadeia de distribuição e à natureza humana". Portanto, considera-se "alimento seguro" o que oferece riscos aceitáveis, reduzidos ao máximo durante a produção (Richards, 2002).

Grande parte das toxinfecções ocorridas nos países latino-americana é ocasionada pela ingestão de alimentos contaminados por microrganismos patogênicos. Aliado a isso, ocorre intoxicações agudas causadas por contaminação química dos alimentos. Richards (2002) afirma que "os principais fatores que determinam as enfermidades transmitidas por alimentos estão relacionados com as condições precárias de produção, armazenamento, transporte, processamento, manipulação, conservação e comercialização". Dados da Organização Mundial da Saúde, citados por alguns autores, afirmam que mais de $70 \%$ dos casos de enfermidades transmitidas pelos alimentos têm origem no seu manuseio inadequado pelo consumidor final (Oliveira, 2002), e que 60\% das doenças de origem alimentar no Brasil são toxinfecções alimentares, causadas por microrganismos como Salmonella sp., Staphylococcus

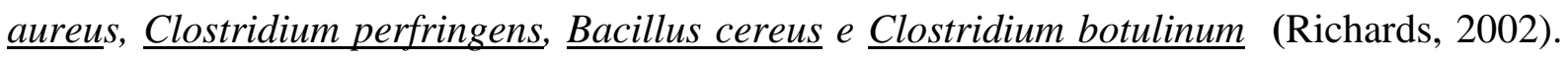
A tabela 1 apresenta alguns dados sobre surtos de doenças veiculadas por alimentos.

Tabela 1: Estimativas de surtos de doenças bacterianas veiculadas por alimentos no estado do Paraná, entre os anos de 1978 e 1995 (SENAI,1999).

\begin{tabular}{|l|c|}
\hline \multicolumn{1}{|c|}{ Patógenos } & Número de surtos \\
\hline Staphylococcus aureus & 217 \\
\hline Salmonella & 95 \\
\hline Clostridium perfringens & 11 \\
\hline Escherichia coli & 23 \\
\hline
\end{tabular}

Pesquisas realizadas no Centro de Enfermidades Infecciosas de Atlanta/USA mostraram que de $4 \%$ a $25 \%$ das amostras de mel de Apis mellifera continham esporos de $\underline{\text { Clostridium }}$ 
botulinum; além disso, relatam que já foi detectada a presença de esporos de botulismo nos méis da Argentina e da federação brasileira. Tais esporos de Clostridium botulinum, consumidos eventualmente, são expelidos pelas fezes, exceto em crianças com menos de 1 ano de idade, que ainda não tem uma microflora intestinal capaz de defendê-las desta bactéria. No período de 1987 a 1997, ocorreram 70 casos de botulismo no Brasil. É provável, no entanto, que este número seja bem maior, devido às falhas na comunicação aos órgãos competentes decorrentes de "erro de diagnóstico" pelos médicos (Nogueira-Neto, 1997).

O mesmo autor informa que, nos Estados Unidos, a Sioux Honey Association, grande associação apícola, recomenda não servir mel a menores de um ano, e cita que, em 1976, na Califórnia, pesquisadores analisaram as fezes de crianças enfermas e descobriram em seus intestinos presença da toxina botulínica. Os mesmos pesquisadores realizaram vários outros estudos para esclarecer o assunto e afirmaram que, em termos mundiais, 34,7 \% dos casos hospitalizados de botulismo infantil estavam associados ao consumo de mel.

Nogueira-Neto (1997) sugere que, como prevenção ao botulismo, não se ofereça mel a crianças menores de um ano de idade, ou para pessoas com a microbiota intestinal insuficiente ou danificada, principalmente no cólon, causada por cirurgias ou pelo uso de antibióticos.

É importante esclarecer a diferença entre intoxicação alimentar e infecção alimentar: "quando o agente é uma toxina previamente elaborada por um determinado microrganismo no alimento, a doença é denominada intoxicação (toxinose) alimentar". São exemplos de intoxicação alimentar: "botulismo, intoxicação estafilocócica, e doenças causadas por micotoxinas. A doença pode não ocorrer por não ter células viáveis no alimento. Porém, "quando a doença envolve a ingestão de células viáveis do microrganismo patogênico, colonização e/ou invasão, a doença é denominada infecção alimentar", e pode-se citar como exemplo a salmonelose. Já quando ocorre "colonização e ação de toxinas", têm-se uma toxinfeç̧ão alimentar, como por exemplo doenças causadas por $\underline{\text { Clostridium perfringens }}$ (SENAI, 1999).

O sistema de Análise de Perigos e Pontos Críticos de Controle - APPCC ou HACCP (da sigla em inglês Hazard Analysis and Critical Control Points) foi desenvolvido pela Pillsbury Company, requisitado pela NASA em 1959 para viabilizar seus primeiros vôos tripulados. É um "sistema preventivo que busca a produção de alimentos inócuos" . As bases 
do APPCC são "princípios técnicos e científicos na produção e manejo dos alimentos" aplicáveis desde “a agricultura e pecuária básica, a industrialização e manipulação, os serviços de alimentação coletiva, os sistemas de distribuição e manejo e na utilização do alimento pelo consumidor" (Almeida, 2002).

Oliveira; Gonçalves; Shinohara e Stamford (2003) afirmam que:

"O sistema APPCC permite demonstrar onde se encontram os pontos de risco que podem trazer prejuízo para a qualidade e higiene dos alimentos e propõe práticas e procedimentos com o objetivo de diminuir, minimizar ou eliminar o impacto desses pontos sobre a qualidade do produto".

Oliveira (2002) garante que o sistema de Análise de Perigos e Pontos Críticos de Controle é um processo científico que tem por finalidade construir a inocuidade nos processos de produção, manipulação, transporte, distribuição e consumo de alimentos. Afirma que o APPCC pode ser considerado como uma proposta sistematizada de identificação, determinação e controle de perigos, sendo um sistema que permite uma "abordagem racional para controle dos perigos microbiológicos dos alimentos", evitando as diversas fragilidades inerentes à proposta de inspeção final, e independente da expectativa da análise microbiológica. Pode ser empregado em todas as etapas da cadeia alimentar de diversos gêneros alimentícios, incluindo produção, processamento, transporte, comercialização, e unidades de alimentação e nutrição.

Com base nessas considerações, o objetivo desse estudo foi: (1) aplicar o sistema APPCC no processamento industrial do mel de abelha Apis mellifera, a partir da obtenção da matéria-prima (mel) até o produto final, procurando identificar os pontos críticos de controle relativos principalmente à segurança do produto; (2) comentar aspectos de importância relativos à qualidade do produto final, nas diversas fases do processo.

Foram considerados Pontos de Controle (PCs) os fatores relacionados à qualidade do produto e às etapas do processamento industrial no qual o controle preventivo de perigos é efetuado com base na aplicação das Boas Práticas de Fabricação (BPFs).

\section{DESENVOLVIMENTO}


A produção mundial de mel gira em torno de 1.200.000 toneladas por ano. Somente a Alemanha compra 50\% de todo o mel exportado no mundo. A China era o principal exportador de mel para a Alemanha, até 1987. Porém, desde 2002, a importação do mel chinês foi suspensa pela Comunidade Européia e pelos EUA devido "aos altos índices de drogas veterinárias encontrados no mel daquele país”. Além disso, os EUA suspenderam, a importação de mel da Argentina (que produz 60.000 ton./ano e consome apenas 10.000 ton./ano), alegando distorções no preço do produto, o que estava promovendo uma concorrência desleal com os próprios produtores americanos. Estes fatos contribuíram para uma elevação significativa no preço do mel, devido ao desequilíbrio oferta-demanda e favoreceu, pela primeira vez, a entrada do Brasil na rota do mercado mundial de mel (EMBRAPA, 2003).

A tabela 2 indica a produção mundial de mel por continente em 2001, e demonstra que a Ásia teve a maior produção.

Tabela 2- Produção mundial de mel no ano de 2001 (Apiservices, 2002).

\begin{tabular}{||l|c||}
\hline \hline Continente & Produção de mel em toneladas \\
\hline África & 145.000 \\
\hline América do Norte & 205.000 \\
\hline América do Sul & 131.000 \\
\hline Ásia & 465.000 \\
\hline Europa & 288.000 \\
\hline Oceania & 29.000 \\
\hline Total & 1.263 .000 \\
\hline
\end{tabular}

A produção mundial de mel, por país, está quantificada na tabela 3. Fica demonstrado que a Argentina é o país da América do Sul que mais produz mel, apesar de ter um território de $2.776 .700 \mathrm{~km}^{2}$, bem menor que o Brasil que possui o território de $8.512 .700 \mathrm{~km}^{2}$, segundo informações da EMBRAPA (2003). A tabela 3 também posiciona o Brasil como o décimo colocado no ranking da produção mundial.

Tabela 3 - Produção mundial de mel, por país, em toneladas, no ano de 2001 (Apiservices, 2002). 


\begin{tabular}{||l|c||}
\hline \hline País & $\begin{array}{c}\text { PRODUÇÃO DE MEL EM } \\
\text { TONELADAS }\end{array}$ \\
\hline China & 256.000 \\
\hline Rússia & 125.000 \\
\hline USA & 100.000 \\
\hline U.E & 111.000 \\
\hline Argentina & 90.000 \\
\hline Turquia & 71.000 \\
\hline Ucrânia & 52.000 \\
\hline México & 56.000 \\
\hline Índia & 52.000 \\
\hline Canadá & 32.000 \\
\hline Brasil & 20.000 \\
\hline Austrália & 19.000 \\
\hline Hungria & 16.000 \\
\hline \hline
\end{tabular}

EMBRAPA (2003) dissemina alguns dados do Sistema de Análise das Informações de Comércio Exterior, denominado Alice-Web, da Secretaria de Comércio Exterior (Secex), do Ministério do Desenvolvimento, Indústria e Comércio Exterior (MDIC), em que as importações e exportações brasileiras tiveram comportamentos inversos: enquanto as importações diminuíram, as exportações aumentaram, conforme tabela 4. Estes dados demonstram o crescimento da produção brasileira de mel, pois não houve redução no consumo do produto.

Tabela 4- Importações e exportações brasileiras de mel natural no período de 1998 a 2001, expressas em toneladas (EMBRAPA, 2003).

\begin{tabular}{||l|c|c|c|c||}
\hline \hline ANO & $\mathbf{1 9 9 8}$ & $\mathbf{1 9 9 9}$ & $\mathbf{2 0 0 0}$ & $\mathbf{2 0 0 1}$ \\
\hline Importações & 2428,8 & 1820,7 & 287,2 & 252,5 \\
\hline Exportações & 16,7 & 18,6 & 268,9 & 1814,4 \\
\hline \hline
\end{tabular}

Nos últimos 15 anos, só no estado do Piauí, a atividade apícola cresceu 94,7\%, com importante expansão entre 1996 e 1998, quando o aumento foi de 39,7\%, numa média de 13,23\% ao ano. Entretanto, entre 1999 e 2000 este incremento foi de apenas 6\%, redução que pode ser atribuída às dificuldades encontradas nos anos de 1998 e 1999, devido ao longo período de estiagem, provocado pelo fenômeno El Niño, quando muitos apicultores perderam entre 80 e 100\% de seus enxames, desistiram da atividade e desmotivaram futuros produtores. O registro de importações de mel pelo país em 1999, em cerca de 20 toneladas, vem confirmar esta ocorrência. Este comportamento também foi confirmado nos registros de 
exportações de mel do Piauí de 1998 a 2001, considerados insignificantes (EMBRAPA, 2003).

\subsection{DESCRIÇÃO DO PRODUTO}

\subsubsection{Considerações gerais sobre mel}

Segundo o Regulamento Técnico de Identidade e Qualidade do mel (BRASIL, 1997), mel é definido como:

"o produto alimentício produzido pelas abelhas melíferas a partir do néctar das flores ou das secreções procedentes das partes vivas das plantas, ou de secreções de insetos sugadores de plantas que ficam sobre partes vivas de plantas, que as abelhas recolhem, transformam, combinam com substâncias específicas próprias, armazenam e deixam maturar nos favos da colméia".

O mel é um líquido viscoso e doce elaborado pelas abelhas a partir do néctar procedente fundamentalmente das flores, o qual é transportado pelas abelhas operárias, em suas bolsas melíferas, até os quadros da colméia, onde armazenam e maturam o néctar que constitui uma reserva de alimento para a época de escassez de floradas (Root, 1984).

O mel pode ser classificado por sua origem botânica como: mel de flores, obtido do néctar das flores; méis uniflorais ou monoflorais, "produto com origem de flores da mesma família, gênero ou espécies e com características sensoriais, físico-químicas e microscópicas próprias"; e méis multiflorais ou poliflorais. (BRASIL, 1997). Além da classificação botânica, o mesmo autor classifica o mel por seu procedimento de obtenção: mel escorrido, obtido pelo escorrimento dos favos desorpeculados sem larvas; mel prensado, obtido pela prensagem dos favos sem larvas; mel centrifugado, obtido pela centrifugação dos favos desorpeculados, sem larvas; e mel filtrado, submetido a um processo de filtração sem alteração de seu valor nutritivo.

O Ministério da Agricultura e do Abastecimento (BRASIL, 1997), no Regulamento Técnico para Fixação de Identidade e Qualidade de Mel, designa a denominação de venda do produto como mel, e permite que seja agregado à palavra mel apenas a sua classificação botânica (como por exemplo: mel de flores, mel monofloral ou unifloral e mel multifloral ou poliflorais). O mesmo autor declara que a composição do mel é: 
"uma solução concentrada de açúcares com predominância de glicose e frutose. Contém ainda, uma mistura complexa de outros hidratos de carbono, enzimas, aminoácidos, ácidos orgânicos, minerais, substâncias aromáticas, pigmentos, cera e grãos de pólen”.

As características gerais do mel, tais como sua composição em açúcares, cor e “flavor” , são conseqüência da fonte floral ou das misturas quando da coleta. Fatores externos como o clima, as condições de coleta, de extração ou de armazenagem do produto podem levar a modificações em suas características. No entanto, a composição química e certos parâmetros físicos de méis apresentam-se dentro de certo intervalo, permitindo seu controle de qualidade (Pereira e Denadai, 1983).

Root (1984) considera o sabor do mel muito variável: alguns são simplesmente doces, outros podem ser classificados como de sabor suave, aromático, perfumado, amargo, áspero, medicinal ou desagradável. Tanto o sabor quanto a cor dependem da fonte em que a abelha extraiu o néctar.

\subsection{AsPeCTOS QUíMICOS DO MEL}

Crane (1987) esclarece que os principais componentes do mel são os açúcares, dos quais 70\% são monossacarídeos (glicose e frutose); 10\% são dissacarídeos (inclusive sacarose) e 17-20 \% são água, no qual os açúcares estão dissolvidos. Além disso, menciona que já foram identificadas 181 substâncias diferentes presentes no mel, e que "a composição exata de qualquer mel depende, principalmente, das fontes vegetais das quais ele é derivado, mas também do tempo, solo e outros fatores, dois méis nunca são idênticos."

Para Root (1984), a composição média do mel é : 41 \% de frutose; 34\% de glicose; 19\% de água; 3,68\% de elementos indeterminados (ferro, cálcio, enxofre, magnésio, potássio, manganês, ácido fosfórico, grãos de pólen, albumina, princípios aromáticos como o terpeno, álcoois superiores como manitol, entre outros); $1,9 \%$ de sacarose; 1,8\% de dextrina, 0,3\% de proteínas; 0,1\% de ácidos; 0,18 \% de cinzas (dos minerais encontrados nas cinzas obtidas após desidratação e combustão do mel, o autor cita ter encontrado: potássio, cloro, enxofre, cálcio, sódio, fósforo, magnésio, silício, ferro, manganês e cobre) e 0,04\% de nitrogênio. 
Outras substâncias estão presentes no mel, como os ácidos: “fórmico, acético, benzóico, butírico, cítrico, isovalérico, láctico, maléico, málico, oxálico, fenilacético, propiônico, piroglutânico, succínico e valérico". Além destes ácidos, o mel contém aminoácidos: prolina (é a mais importante), lisina, ácido glutâmico, ácido aspártico, alanina, arginina, cistina, glicina, histidina, isoleucina, leucina, metionina, fenilalanina, serina, treonina, triptofano, tirosina, valina. Tais aminoácidos favorecem a identificação dos tipos de méis e de substâncias sintéticas disfarçadas em mel ou fraudes (Crane, 1987)

Crane (1987) ressalta que o constituinte secundário de mel é o hidroximetilfurfural, comumente chamado HMF. Este composto resulta da quebra de açúcares hexoses, tais como glicose e frutose, na presença de um ácido, e assume grande importância no controle de qualidade do mel, pois sua quantidade numa amostra de mel é usada como indicador direto da qualidade. A quantidade de HMF aumenta em méis submetidos a altas temperaturas, sendo seu limite de 40 ppm.

Crane (1987) declara que existem três enzimas importantes no mel: “invertase, diastase (amilase) e glicose-oxidase”. Outras enzimas, incluindo a catalase e a fosfatase ácida, podem estar presentes.

Segundo informações da série Qualidade e Segurança Alimentar, do Serviço Nacional de Aprendizagem Industrial (SENAI, 1999), o mel apresenta $A_{W}$ abaixo de 0,60.

\subsection{PROPRIEDADES FÍSICAS E FISICO-QUÍMICAS DO MEL}

As propriedades físicas e físico-químicas do mel são determinadas pelos seus constituintes, neste trabalho serão abordados apenas os que são de maior importância econômica na industrialização do mel.

\subsubsection{A cristalização do mel}


As abelhas produzem os méis na forma líquida, como soluções supersaturadas, e quando ficam expostos a uma temperatura abaixo da colméia $\left(10-20^{\circ} \mathrm{C}\right)$ iniciam um processo de cristalização (Crane, 1987).

A cristalização do mel está relacionada com a composição e condições de armazenamento do produto. A proporção entre os dois principais açúcares do mel frutose e glicose influenciam em sua cristalização (Faria, 1983).

Root (1984) declara que todos os tipos de mel cristalizam naturalmente (alguns em poucas semanas e outros demoram anos para completar sua cristalização). Esclarece que a velocidade de cristalização depende da proporção de açúcares (frutose e glicose), do conteúdo de umidade do mel, da temperatura de armazenamento e da presença ou ausência de cristais primários (chamados de "sementes de cristalização ou núcleos de cristalização"). Afirma que, quanto mais rápido acontece a cristalização, mais finos serão os cristais. Crane (1987) também diz que o processo de cristalização do mel depende da ausência ou presença de partículas sólidas em suspensão, que servirão como "núcleo para crescimento de cristal". Tais núcleos existem naturalmente no mel, porém são invisíveis macroscopicamente e constituem "cristais diminutos, bolhas de ar, partículas de cera de abelhas, grãos de pólen, sujeira do ar ou do recipiente do mel".

“As partículas em suspensão (impurezas, grãos de pólen e bolhas de ar) induzem a formação de cristais pelo efeito denominado nucleação. Os cristais provenientes deste mecanismo são pequenos e uniformes. A destruição destes cristais por aquecimento resulta em recristalização irregular e em formação de grandes cristais” (Faria, 1983).

Todos os tipos de mel contêm colóides suspensos em seu centro. Tais colóides não são impurezas (geralmente, encontram-se quantidades apreciáveis de proteínas, partículas de cera, grãos de pólen e silício entre os colóides do mel), pois as impurezas podem ser eliminadas através de filtração e/ou decantação, fato que não ocorre com os colóides (Root, 1984).

Faria (1983) complementa que os cristais formados no mel são "compostos de glicose mono-hidratada, quando a solução atinge uma supersaturação e temperatura crítica", observando que a relação glicose/água no sistema tem sido usada como critério para avaliar a tendência à cristalização. 
Crane (1987) complementa que para a comercialização de mel líquido este é submetido a temperaturas de $60^{\circ}-71^{\circ} \mathrm{C}$ para "dissolver cristais e para expelir o ar incorporado". Em seguida, por filtração, removem-se todas ou a maioria das partículas sólidas, inclusive o pólen. A retirada deste pólen impede a determinação da origem floral do mel.

De acordo com Faria (1983), o mel somente cristaliza abaixo da temperatura de transição $\left(30^{\circ} \mathrm{C}\right)$, sendo $14^{\circ} \mathrm{C}$ o nível de calor mais eficiente para ocorrer a cristalização, podendo acontecer mais intensamente em temperaturas inferiores à ideal quando a umidade for mais elevada.

O maior risco da granulação do mel é o favorecimento da fermentação, observa o autor, destacando que a glicose é o monossacarídeo responsável pela granulação do mel. O maior problema resultante da precipitação de glicose é o aumento do teor de umidade da fase líquida, que permite que células de leveduras osmofílicas (microorganismos que se desenvolvem em condições desfavoráveis: atividade de água baixa e concentração de glicídios alta), que ocorrem naturalmente no mel, se multipliquem e provoquem a fermentação do produto (Root, 1984).

Faria (1983) também manifesta que a formação de cristais de glicose favorece o crescimento de leveduras, devido à maior atividade da água na fase líquida, alterando a qualidade do mel pela aparência e sabor indesejáveis.

\subsubsection{Densidade e viscosidade do mel}

A densidade relativa do mel situa-se entre 1,40 e 1,44 a $20^{\circ} \mathrm{C}$, dependendo do seu conteúdo de água (Crane, 1987).

O peso específico médio do mel é de 1,439, à temperatura ambiente, ou 1,409 aos $71^{\circ} \mathrm{C}$ (Root, 1984).

Quanto à viscosidade, Root (1984) diz que "a densidade, ou escassa fluidez do mel, habitualmente é conhecida como corpo. Há méis espessos, de bom corpo e de viscosidade elevada, e também méis leves, líquidos e de viscosidade baixa”. O autor esclarece que a 
viscosidade do mel está relacionada diretamente à sua temperatura, ou seja, ele liquefaz-se à medida que é aquecido, apresentando o máximo aumento de fluidez aos $38^{\circ} \mathrm{C}$. Após $50^{\circ} \mathrm{C}$, o incremento de fluidez por grau de aumento de temperatura é mínimo.O autor sugere que os méis sejam mesclados a temperaturas de $38^{\circ}$ para atingir homogeneidade perfeitamente satisfatória. Além da temperatura, outros fatores que alteram a viscosidade do mel são a umidade e sua composição química (como dextrinas, que aumenta a viscosidade do produto, e a relação frutose/ glicose, sendo que, quanto mais frutose, menos viscoso torna-se o mel).

\subsubsection{Higroscopicidade do mel}

Por se tratar de uma solução densamente concentrada de açúcar, o mel é altamente higroscópico. Absorve água muito facilmente sob certas condições: depende do seu conteúdo de água, da umidade relativa do ar (UR), da temperatura atmosférica. Se a UR for de $60 \%$, méis com 18,3 \% de água perderão água para o ambiente (Crane, 1987).

Faria (1983) explica que o ganho de umidade acontece por meio de "equilíbrio higroscópico", e que para cada "condição de umidade relativa do ar sobre o mel existe uma umidade de equilíbrio correspondente", sendo que para méis com 21\% de umidade, a umidade relativa do ar de equilíbrio é de $65 \%$. Se esta mesma amostra de mel for submetida à UR de 80\%, resultará em um ganho de umidade equivalente a 33\%.

Root (1984) menciona que méis com 17,4\% de umidade mantêm-se estáveis higroscopicamente em ambientes com UR de 58\%, e considera $60 \%$ como a umidade relativa ótima para armazenar e conservar méis.

A elevada higroscopicidade do mel é atribuída à frutose, que é o açúcar mais solúvel em água, e quanto mais baixa sua concentração, menor a probabilidade de ocorrer a cristalização (Faria, 1983).

\subsection{Aspectos MiCROBIOLÓGICOS DO MEL}

2.5.1 Leveduras e fermentação do mel 
Quanto maior a umidade do mel, mais elevada será sua atividade de água, e conseqüentemente, maior será a propensão de crescimento de microrganismos, sendo que as leveduras osmofílicas desenvolvem-se em baixa atividade de água. Méis com umidade acima de $30 \%$, com pH elevado, também favorecem o crescimento de fungos, bactérias e outros microrganismos (Faria, 1983).

Documento da série Qualidade e Segurança Alimentar (SENAI, 1999) esclarece que a atividade de água $\left(\mathrm{A}_{\mathrm{W}}\right)$ é outro parâmetro importante para o desenvolvimento microbiano, sendo que "a possibilidade de alteração microbiana em alimentos" cessa em alimentos apresentando $A_{W}$ abaixo de 0,60, embora isso não signifique destruição dos microrganismos.

O conteúdo de água do mel e o número de células fermentadas determinam se o mel fermentará a uma determinada temperatura. "Todos os méis naturais contêm leveduras tolerantes ao açúcar, das quais foram identificadas espécies de Zygosaccharomyces, duas de Saccharomyces e uma espécie de cada um desses gêneros: Nemastopora, Schizosaccharomyces, Schwanniomyces e Torula". O néctar e o melato têm leveduras naturalmente, e outras podem ser acrescentadas através do corpo da abelha, do solo, ao redor da colméia, do ar do apiário e dos equipamentos (Crane, 1987).

Faria (1983) afirma que "todo mel contém leveduras; mel cristalizado favorece a fermentação; temperaturas abaixo de $10^{\circ} \mathrm{C}$ evita a fermentação; aquecimento de mel a $65^{\circ} \mathrm{C}$ por 30 minutos destrói as leveduras e, conseqüentemente, controla a fermentação".

Root (1984) enfatiza que os microrganismos que preferencialmente atuam em soluções açucaradas são as leveduras, principalmente quando tais soluções contêm certo grau de acidez. Assegura que todos os méis são contaminados por leveduras em diferentes graus de contaminação, e cita que já foram encontrados 20 tipos diferentes de leveduras capazes de provocar a fermentação no mel.

Segundo Root (1984), os principais meios ou fontes de contaminação do mel, por intermédio das leveduras são os seguintes : as flores visitadas pelas abelhas, ou seja, a abelha é portadora de leveduras e contamina sua colméia e o néctar armazenado na colméia; o solo do apiário, que é uma grande reserva de leveduras, principalmente em apiários mais antigos, 
onde restos de abelhas, néctar e cera contaminados com leveduras caem naturalmente no solo, recontaminando e reinfestando as colméias pela colaboração do vento e de outros insetos; e a contaminação durante a extração do mel, na qual o apicultor é o principal agente contaminador do produto extraído.

A fermentação do mel é totalmente indesejável, exceto para a produção de bebidas alcoólicas. A melhor segurança contra a fermentação é um alto conteúdo de açúcar e um baixo conteúdo correspondente de água. Se o conteúdo de água chegar a 17\%, o mel nunca fermentará, mesmo se muitas células fermentadas estiverem presentes. Méis com 18\% de umidade são permissíveis de muitas células fermentadas, e 19\% é o limite crítico. Uma temperatura de armazenagem abaixo de $11^{\circ} \mathrm{C}$ desencoraja a fermentação, mas entre $11-21^{\circ} \mathrm{C}$ a fermentação pode ser induzida. Temperaturas entre $21^{\circ}$ e $27^{\circ} \mathrm{C}$ são menos prováveis de induzir tanto a fermentação quanto a cristalização, porém enzimas são destruídas e o HMF é produzido rapidamente, escurecendo o mel. Acima de $27^{\circ} \mathrm{C}$ não ocorre fermentação, mas o dano é maior. A temperatura ótima de estocagem do produto deve ser a mais baixa possível, $11^{\circ} \mathrm{C}$ ou menos (Crane, 1987).

Root (1984) cita que a fermentação depende da umidade e da temperatura de armazenamento, sendo que o mel com umidade alta não fermentará se submetido a temperaturas inferiores aos $10^{\circ} \mathrm{C}$. Aos $15,5^{\circ} \mathrm{C}$, a fermentação ocorre de maneira mais rápida que em temperaturas maiores, devido à condição ideal para provocar a cristalização, o que favorece a fermentação. Ele acrescenta que a melhor maneira de evitar a fermentação é pelo aquecimento a $71^{\circ} \mathrm{C}$ por 1 minuto, ou $60^{\circ} \mathrm{C}$ por 30 minutos, homogeneizando o mel constantemente, o que possibilita podendo armazenar o produto em embalagem fechada por até quatro anos, ocorrendo apenas perdas de qualidade em relação à cor e ao sabor.

\subsubsection{Contaminação do mel e multiplicação microbiana}

Segundo Faria (1983), já foram isolados 14 espécies de leveduras no mel de abelhas, e ele afirma que a presença de leveduras osmofílicas (tolerantes ao açúcar) no mel poderá promover fermentação, se existirem condições favoráveis ao crescimento destes microorganismos. Também assegura que a absorção de umidade torna o mel um meio de cultura ideal, e que se pode evitar a passagem de umidade do ar ambiente para o mel com o uso de embalagem adequada. 
Além das condições de temperatura e umidade ideais, a intensidade de fermentação dependerá do "número inicial de leveduras", ou seja das condições higiênicas durante a extração e manipulação do mel, conforme tabela 5.

Tabela 5 - Relação da possibilidade de fermentação em relação ao teor de umidade para méis (Faria, 1983).

\begin{tabular}{||l|l||}
\hline \hline Teor de Umidade (\%) & Possibilidade de Fermentação \\
\hline$<\mathbf{1 7}$ & $\begin{array}{l}\text { Não-fermentável, independentemente do } \mathrm{n}^{\text {o }} \text { de } \\
\text { leveduras }\end{array}$ \\
\hline $\mathbf{1 7 , 1}-\mathbf{1 8 , 0}$ & Não-fermentável, se o $\mathrm{n}^{\circ}$ de leveduras $<1000 / \mathrm{g}$ \\
\hline $\mathbf{1 8 , 1}-\mathbf{1 9 , 0}$ & Não-fermentável, se o $\mathrm{n}^{\circ}$ de leveduras $<10 / \mathrm{g}$ \\
\hline $\mathbf{1 9 , 1}-\mathbf{2 0 , 0}$ & Não-fermentável, se o $\mathrm{n}^{\circ}$ de leveduras $<1,01 / \mathrm{g}$ \\
\hline$>\mathbf{2 0}$ & Sempre fermentável \\
\hline \hline
\end{tabular}

Quanto à contaminação durante a extração do mel, Root (1984) ressalta que depende do apicultor minimizar ou eliminar as possibilidades de contaminar o produto durante esse processo. Destaca que o ar e as superfícies da sala de extração, os utensílios, os recipientes e os canos ou tubos de condução de mel são os principais meios de contaminação do produto. Sugere que o apicultor adote medidas higiênicas para prevenir a contaminação durante a extração e posterior armazenamento, evitando a desnaturação do mel e obtendo um produto de melhor qualidade, menos propenso à fermentação. Tais medidas podem ser abreviadas como sala de extração, utensílios, recipiente e tubos de condução devidamente limpos e sanitizados.

$\mathrm{O}$ pH é um fator fundamental na limitação dos tipos de microrganismos que se desenvolverão nos alimentos. O pH 4,5 tem grande importância na microbiologia dos alimentos, pois limita o desenvolvimento de bactérias patogênicas e de $\underline{\text { Clostridium }}$ botulinum. Os alimentos ácidos ( $\mathrm{pH} 4,0$ a 4,5) têm microflora bacteriana restrita, "representada por bactérias láticas e algumas esporuladas do gênero Bacillus e Clostridium, que produzem esporos de baixa resistência térmica". A maioria dos patógenos não se multiplica, apenas os bolores e leveduras encontram nesta faixa de $\mathrm{pH}$ ótimas condições para desenvolvimento (Documento da série Qualidade e Segurança alimentar, SENAI, 1999). 
"A multiplicação microbiana ocorre em função do tipo de alimento e das condições ambientais. Os processos de conservação dos alimentos fundamentam-se na eliminação total ou parcial dos microrganismos capazes de alterar o alimento". A pasteurização utiliza temperatura suficiente para eliminar total ou parcialmente a microbiota do alimento (Documento da série Qualidade e Segurança alimentar, SENAI, 1999).

\subsection{ASPECTOS TECNOLÓGICOS NO PROCESSAMENTO DO MEL}

\subsubsection{Transformações no mel}

Ocorrem outras transformações no mel, além da fermentação, da cristalização e do escurecimento. São alterações de ordem física, química e biológica que afetam o sabor e o aroma típicos do mel. Essas características variam em função da origem do mel e "são manifestadas pelo conjunto de cerca de 120 compostos voláteis e não-voláteis presentes". Tais componentes, geralmente, são afetados pela "temperatura, umidade relativa, oxigênio e luminosidade do ambiente de estocagem e comercialização. As mudanças dos componentes voláteis são acentuadas durante o aquecimento, devido ao aumento da pressão de vapor destes compostos, resultando uma maior volatilização, ou pela formação de outros compostos derivados de reações de escurecimento não-enzimático." (Faria, 1983).

A mudança da coloração do mel é proveniente de um efeito acumulativo de aquecimentos de pasteurização ou de temperatura ambiente de estocagem relativamente alta. A temperatura catalisa reações químicas originando pigmentos de cor vermelha. O HMF (hidroximetilfurfural) é um composto de cor vermelha formado pelo efeito do aquecimento de soluções de sacarose, glicose e frutose. Tal reação é mais rápida com a frutose em meio ácido, do que com os demais açúcares. Devido à acidez característica do mel, mesmo em um aquecimento gradual poderá ocorrer alteração de sua coloração. Em conseqüência desta tendência, "a presença de grande quantidade de HMF tem sido usada como suspeita de adulterações do mel pela adição de açúcares invertidos (solução de frutose e glicose)". E, explica que "todo o mel comercial apresenta cerca de 1,24 mg/100 g de HMF após a extração" (Faria, 1983).

Faria (1983) cita outros fatores responsáveis pela alteração da cor do mel : reação de Maillard (aminoácido + açúcares), que é intensificada pela umidade elevada; o pH que 
também tem efeito positivo em reações de escurecimento; e a adulteração com açúcar invertido por meio de solução ácida, que também poderá acelerar o escurecimento.

Root (1984) afirma que o aquecimento provoca escurecimento e danos ao sabor do mel, e sugere que para evitar tais danos o ideal é aquecer o mel até $71^{\circ} \mathrm{C}$, envasá-lo imediatamente e resfriá-lo rapidamente, minimizando as perdas. Complementa que alguns autores asseguram que não é necessário aquecer o produto acima de $50-55^{\circ} \mathrm{C}$. Porém, nesse caso, é necessário mantê-lo quente por um tempo mais prolongado, o que causa maiores danos do produto que se aquecê-lo a temperaturas maiores $\left(71^{\circ} \mathrm{C}\right)$ por menos tempo, resfriando-o rapidamente.

\subsubsection{A pasteurização do mel}

A pasteurização é um tratamento térmico que destrói grande parte dos microrganismos existentes no alimento, sendo que para eliminar os patogênicos utiliza-se temperatura de $62{ }^{\circ} \mathrm{C}$ por 30 minutos. Nos alimentos ácidos, os patogênicos não resistem e nem se desenvolvem

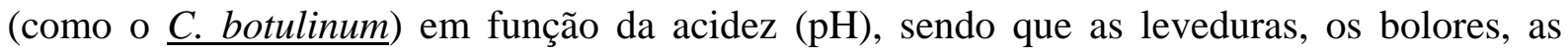
bactérias láticas e acéticas e alguns esporulados (como da espécie Clostridium) são capazes de multiplicar-se. “O pH é um fator crítico”, sendo que para alimentos com $\mathrm{pH}$ acima de 4,5 a pasteurização não destrói o esporo de $\underline{C}$. botulinum, que pode germinar e provocar intoxicação (Documento da série Qualidade e Segurança alimentar, SENAI, 1999).

O calor destrói as células dos microrganismos; a temperatura letal varia de acordo com a espécie do microrganismo e da forma em que ele se encontra. As células vegetativas destroem-se, geralmente, em torno dos $60^{\circ} \mathrm{C}$, e os esporos são "inativados em temperaturas superiores a $100^{\circ} \mathrm{C}$, de um modo geral." O tempo a uma dada temperatura é essencial para a eliminação de uma população de microrganismos (Documento da série Qualidade $e$ Segurança alimentar, SENAI, 1999).

\subsubsection{Embalagens para mel}


Faria (1983) assegura que os recipientes de vidro constituem as embalagens que mais protegem o mel, devido "à inércia do vidro em relação ao mel", e explica que os vidros são compostos por uma mistura de óxidos orgânicos de composição variada. O autor diz que:

"os silicatos de sódio e cálcio contribuem para 75\% da composição destes recipientes e que os demais óxidos encontrados conferem características de resistência ao impacto e ao aquecimento formando uma barreira contra os raios luminosos incidentes sobre o produto acondicionado".

Como principais desvantagens, do uso de recipientes de vidro, o mesmo autor menciona: "custo unitário elevado, grande peso em relação ao produto, sua fragilidade e os defeitos de vedação das tampas".

\subsection{Aspectos higiênico-sanitários no processamento de alimentos e segurança alimentar}

Uma das condições para a promoção e a manutenção da saúde é uma alimentação dentro dos padrões higiênicos satisfatórios, sendo que a deficiência nesse controle é um dos fatores responsáveis pela ocorrência de surtos de doenças transmitidas por alimentos (Oliveira; Gonçalves;Shinohara; Stamford, 2003).

Para Souza; Lima e Narain (2003), "a indústria alimentícia tem como propósito a produção de alimentos com uma longa vida útil ligada a uma inocuidade no que diz respeito à presença de microrganismos patogênicos e suas toxinas".

Para Makiya e Rotondaro (2002), o dilema relacionado à "segurança de alimentos” tem se tornado assunto de importantíssima ordem, primeiro pela sua relevância natural, segundo pelas ocorrências de infecções alimentares mundiais e das suas conseqüências dramáticas“.

Segundo Silva Junior (2001), um alimento contaminado causa danos não só a saúde do indivíduo como também à empresa (contratada e contratante) e à sociedade como um todo.

Oliveira (2002) diz que são vários os agentes da cadeia produtiva que desempenham um papel fundamental para garantir a manutenção da inocuidade dos alimentos, e cita-os: "autoridades governamentais, produtores agropecuários, transportadores de matéria-prima e produtos industrializados, indústrias processadoras atacadistas, varejistas, universidades, empresas de comunicação social e o consumidor". 
Almeida (2002) ratifica a importância de iniciativas que garantam a inocuidade dos alimentos, declarando ser "necessário dar ênfase ao desenvolvimento e implementação de medidas preventivas para o controle dos riscos em alimentos, através da colaboração entre autoridades governamentais e os setores responsáveis da indústria de alimentos" (Dr. Franz Fishler, apud Conferência Inocuidade dos Alimentos - Um Debate Nacional, realizada em Londres em 03 de setembro de 1997).

\subsection{Doenças transmitidas por alimentos (DTA's)}

Em seguida serão abordadas algumas informações relevantes sobre microrganismos envolvidos em algumas doenças transmitidas por alimentos e algumas medidas de prevenção, controle e eliminação das DTA’s

\subsubsection{Escherichia coli:}

São naturalmente encontradas no trato gastrintestinal de todos os animais, inclusive humanos. Infecção alimentar por E.coli causa "dor abdominal, diarréia aquosa ou sanguinolenta, febre, náusea e vômito". Como medidas preventivas pode-se usar o aquecimento $\left(65^{\circ} \mathrm{C}-74^{\circ} \mathrm{C}\right)$, a prevenção de contaminação cruzada pós-processamento e oposição de que manipuladores doentes trabalhem com os alimentos (SENAI, 1999).

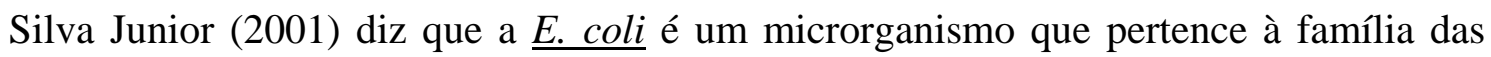
Enterobacteriaceae e ao grupo denominado coliformes fecais, que são fermentadores de lactose e produzem gás a $44,5^{\circ} \mathrm{C}$. O autor considera a E.coli importante não só como patógeno, mas também como um bom indicador de contaminação e de condutas inadequadas de manipulação, e sugere que para o monitoramento do processo de higiene faça-se um exame de cultura das mãos dos manipuladores e ressalta que os resultados serão válidos como monitoramento do processo de higiene, apenas quando as amostras forem colhidas após a higienização das mãos (lavagem e anti-sepsia). Isto é confirmado por Oliveira; Gonçalves; Shinohara; Stamford, 2003 que explicam que a presença de coliformes fecais indica que ocorreu uma grave contaminação fecal após a sanitização do processo, caracterizando também práticas deficientes de higienização das mãos dos manipuladores 


\subsubsection{Staphylococcus aureus:}

Espécie do gênero Staphylococcus, é um dos patógenos de maior potencial para os humanos, sendo uma das mais freqüentes causas de gastroenterite de origem alimentar em todo o mundo, causado principalmente por enterotoxinas. Algumas cepas de Staphylococcus aureus produzem diversas toxinas e enzimas participantes do mecanismo de patogeneicidade. A intoxicação estafilocócica é provocada pela ingestão de alimentos contendo enterotoxinas pré-formada, com ou sem células vegetativas. São encontrados principalmente nos humanos e pertencem à flora natural das mucosas e pele, colonizando as mucosas nasal e oral, podendo alojar-se no períneo, pele e cabelo de indivíduos saudáveis. A disseminação do Staphylococcus aureus entre os humanos e dos humanos para os alimentos pode ocorrer por contato direto ou indireto, pelos fragmentos de pele e secreções do trato respiratório e pela falta de higiene ou comportamento inadequado dos manipuladores (SENAI, 1999).

Segundo Oliveira; Gonçalves; Shinohara e Stamford (2003), este microrganismo é freqüentemente causador de surtos de toxinfecção alimentar, sendo o homem e os animais seus reservatórios primordiais. No homem, a cavidade nasal é o habitat principal dos estafilococos, que a partir deste foco, alcançam à epiderme, as lesões cutâneas, o ambiente e qualquer superfície ou objeto. Informação corroborada pelos autores Cardoso e Araújo (2003), que confirmam sua presença na mucosa nasal, garganta e pele e, ainda explicam que sua presença em alimentos está associada ao manuseio sob condições precárias de higiene.

Outro aspecto relevante para a saúde pública é a termo-resistência da toxina estafilocócica, mostrando-se estável mesmo quando submetida a $100^{\circ} \mathrm{C}$ por 30 minutos (Cardoso e Araújo, 2003).

Conforme descrito por Oliveira; Gonçalves; Shinohara e Stamford (2003) "S.aureus é produtor de enterotoxinas e quando ingerido junto com o alimento provocam, após um período de incubação de 1 a 6 horas, sintomas como vômitos, diarréias, dores abdominais e prostração" e o Documento da série Qualidade e Segurança alimentar (SENAI, 1999) expõe que as principais medidas preventivas para evitar intoxicação por Staphylococcus aureus são: o uso adequado de tempo e temperatura de processamento a fim de diminuir a ação das enterotoxinas e treinamento eficaz para que os manipuladores sigam um programa eficaz de Boas Práticas de Fabricação e Higiene Pessoal. 


\subsubsection{Salmonella spp.}

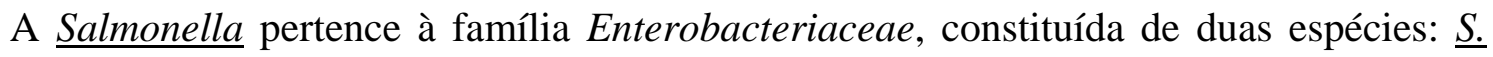

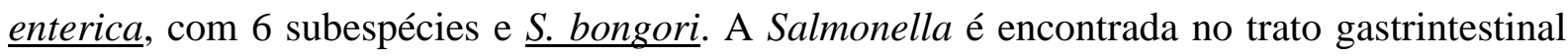
dos mamíferos, pássaros, anfíbios e répteis, sendo um dos enteropatógenos mais incriminados em casos e surtos de origem alimentar em diversos países, inclusive no Brasil (SENAI, 1999).

A Salmonella habita o trato intestinal dos mamíferos e das aves. A dose infectiva é baixa, e a legislação prevê ausência de Salmonella em 25 g de produto. A Salmonella é termolábil, tendo redução significativa de células viáveis a temperaturas de $65^{\circ}-75^{\circ} \mathrm{C}$. "Manipuladores com quadro de gastrenterite devem ser imediatamente afastados" (Cardoso e Araújo, 2003).

A Salmonelose é uma doença infecciosa sendo portanto necessária a presença da bactéria, e provoca "náusea e vômito, dores abdominais e febre". A dose infectiva é extremamente variável, sendo "relativamente alta para indivíduos saudáveis e, baixa para indivíduos de risco (como por exemplo idosos e imunocomprometidos)” conforme documento da série Qualidade e Segurança alimentar, SENAI, (1999).

\subsubsection{Clostridium botulinum}

SENAI (1999) no documento da série Qualidade e Segurança alimentar, explica que são reconhecidas quatro categorias de botulismo humano (de origem alimentar, infantil, de lesões e a quarta categoria que inclui todos os casos de origem desconhecida). Afirma também

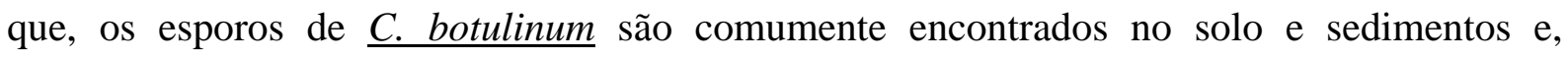
eventualmente, no mel contaminado pelas abelhas. Para efeito deste estudo, serão abordadas as categorias de origem alimentar e infantil.

Segundo Nogueira-Neto (1997), o Clostridium botulinum é uma bactéria estritamente anaeróbica, que praticamente não se multiplica em ambiente com oxigênio livre. Tal bactéria é produtora de uma potente toxina, causadora de um tipo de intoxicação conhecida como 
botulismo. O Clostridium botulinum é muito comum na natureza, sobrevive consumindo matéria orgânica existente nos solos, nos esgotos, no esterco, em rações e em certos alimentos.

Quando em condições favoráveis à reprodução, os esporos de Clostridium botulinum originam formas vegetativas da bactéria. O maior perigo está no consumo de alimentos crus pois tais esporos são formas muito resistentes de propagação. Os esporos e a toxina produzida são destruídos a $80^{\circ} \mathrm{C}$ durante 30 minutos (Nogueira-Neto, 1997).

Segundo o documento da série Qualidade e Segurança alimentar (SENAI, 1999) o botulismo de origem alimentar pode variar de um quadro benigno até quadro grave levando à morte em 24 horas. Os sintomas são: "náusea, vômito, distúrbios neurológicos, diplopia, pupilas fixas e dilatadas, dificuldade de falar e engolir, boca seca, garganta e língua secas, dor na garganta, cansaço e perda de coordenação muscular e falência respiratória". Além disso, pode-se citar outros sintomas gastrintestinais como: dores abdominais, diarréia ou constipação. As principais causas de morte são: falha respiratória e obstrução da entrada de ar.

O mesmo autor explica que a termoresistência dos esporos possibilita a sua sobrevivência em temperaturas normais de cocção e, por serem anaeróbios, crescem em embalagens a vácuo e em ambientes de atmosfera modificada. Como medidas preventivas pode-se controlar inibindo a germinação dos esporos e a proliferação de formas vegetativas, com conseqüente produção de neurotoxinas, pela temperatura máxima de 45-50•C, pH mínimo de 4,6-5,0 e atividade de água mínima de 0,94-0,97.

\subsubsection{Clostridium perfringens tipo A}

O documento da série Qualidade e Segurança alimentar (SENAI, 1999) explica que o C. perfringens é comumente encontrado no solo, poeira e trato gastrintestinal de animais. Produzem doenças de largo espectro como: "toxinfecção alimentar e enterite necrótica" em animais e humanos. Sua patogeneicidade está associada à capacidade de produzir toxinas de natureza protéica, das quais duas são particularmente ativas no trato gastrintestinal de humanos: "enterotoxina de Clostridium perfringens e $\beta$ toxina", que podem causar doenças de origem alimentar. Seu tempo de geração é curto (10 minutos), facilitando uma acelerada multiplicação no alimento, atingindo rapidamente sua dose infectante. Os esporos de 
Clostridium perfringens são muito resistentes ao "estresse ambiental, como à radiação, à dessecação e o calor"

O mesmo autor considera que as toxinfecções causadas por Clostridium perfringens tipo A apresentam sintomas suaves e indefinidos como dores abdominais, gases e diarréia atribuídos a uma enterotoxina produzida pela esporulação da bactéria, no intestino. E que os fatores envolvidos são: contaminação dos equipamentos e higiene pessoal deficiente.

Esclarece também, que os esporos de algumas cepas de Clostridium perfringens são resistentes a temperaturas altas como $100^{\circ} \mathrm{C}$ por uma hora, sendo sua presença em alimentos praticamente inevitável. Cita como medidas preventivas a prevenção de contaminação cruzada, a manutenção das salas de processamento de alimento livres de terra e poeira e $\mathrm{s}$ higienização e sanitização dos equipamentos e das superfícies que entram em contato com os alimentos além do uso de métodos eficazes de Higiene Pessoal e Boas Práticas de Fabricação.

Na tabela 6, pode-se ter um resumo dos principais parâmetros que influenciam o desenvolvimento de microrganismos envolvidos em DTA’s.

Tabela 06: Resumo dos parâmetros que influenciam no desenvolvimento de microrganismos (SENAI, 1999).

\begin{tabular}{|l|c|c|c|c|c|}
\hline Parâmetros & Salmonella & $\frac{\text { Escherichia }}{\text { coli }}$ & $\frac{\text { Clostridium }}{\text { botulinum }}$ & $\frac{\text { Clostridium }}{\text { perfringens }}$ & S. aureus \\
\hline $\begin{array}{l}\text { Temperatura } \\
\text { Mínima }\end{array}$ & $0 \pm 2,0^{\circ} \mathrm{C}$ & $2,5^{\circ} \mathrm{C}$ & $10^{\circ} \mathrm{C}$ & $10^{\circ} \mathrm{C}$ & $5,6{ }^{\circ} \mathrm{C}$ \\
\hline $\begin{array}{l}\text { Temperatura } \\
\text { Máxima }\end{array}$ & $45,6{ }^{\circ} \mathrm{C}$ & $49,4{ }^{\circ} \mathrm{C}$ & $50{ }^{\circ} \mathrm{C}$ & $5{ }^{\circ} \mathrm{C}$ & $50^{\circ} \mathrm{C}$ \\
\hline pH mínimo & 3,7 & 4,0 & 4,6 & 5,0 & 4,3 \\
\hline pH máximo & 9,5 & 9,0 & 9,0 & 9,0 & 9,3 \\
\hline $\mathrm{A}_{\mathrm{W}}$ mínimo & 0,945 & 0,95 & 0,94 & 0,93 & 0,83 \\
\hline
\end{tabular}




\subsection{Medidas PReVentivas PaRa controle De DTA’S}

Os autores Oliveira; Gonçalves, Shinohara e Stamford (2003) relatam que:

"os enteroparasitas podem ser transmitidos por fontes de infecção humana ou animal, através de alimentos ou água contaminados com fezes de indivíduos infectados, principalmente devido a práticas higiênicas deficientes de manipuladores de alimentos”.

Os autores explicam que grande parte da contaminação microbiana dos alimentos origina-se da ignorância e displicência dos manipuladores, das condições sanitárias precárias do local de produção, dos utensílios, da distribuição e comercialização. "Além dos manipuladores, os equipamentos e utensílios mal higienizados têm sido incriminados em surtos de doenças de origem alimentar".

Para Oliveira; Gonçalves, Shinohara e Stamford (2003), os "manipuladores de alimentos", são indivíduos que executam operações manuais em qualquer etapa da "produção, processamento, embalagem, armazenamento, transporte, distribuição e venda de algum alimento". Afirmam que para assegurar a qualidade dos alimentos servidos é necessário ensinar e treinar os manipuladores constantemente, gerando assim um "conjunto de meios e processos" onde o indivíduo é instruído e capacitado para executar as tarefas.

Richards (2002), insiste que:

“a contaminação do alimento por agentes etiológicos (bactérias, vírus, fungos e parasitos) deve-se às práticas inadequadas de manipulação, matériasprimas contaminadas, falta de higiene durante o processamento, além de equipamentos e estrutura operacional deficiente e principalmente inadequação na produção e limpeza de equipamentos envolvendo a relação tempo e temperatura.”

Para garantir a sanidade dos alimentos, o bem estar dos consumidores, e para evitar a ocorrência de surtos de origem alimentar é fundamental implantar procedimentos padronizados de lavagem dos utensílios e as mãos dos manipuladores, através de treinamento e implantação de um eficaz "Manual de Boas Práticas de Fabricação e Higiene Pessoal" (Oliveira; Gonçalves, Shinohara e Stamford, 2003) 
Consoante Silva, Oliveira e Stamford (2003), a produção de alimentos seguros é de fundamental importância na indústria de alimentos. "O risco de contaminação alimentar por microrganismos patogênicos tem sido reconhecido há muitos anos, sendo as bactérias implicadas como principais contaminantes."

Oliveira (2002) afirma que muitos dos organismos que causam doenças são parte integrante da flora gastrintestinal dos animais produtores de alimento, e que os alimentos podem contaminar-se nas várias etapas de processamento, devido ao mau funcionamento ou limpeza inadequada do equipamento, ao uso de material de limpeza, a infestação de insetos e roedores ou armazenamento inadequado.

Silva, Germano e Germano (2003) afirmam que "um programa de treinamento em segurança alimentar pode beneficiar tanto os consumidores quanto os próprios funcionários", e que conhecimentos básicos de microbiologia podem incentivar a prática adequada de manipulação dos alimentos. Salientam, também, que o primeiro passo no sistema de treinamento é a "identificação dos aspectos que realmente necessitam de treinamento", visando atender às necessidades. Tais autores também sugerem que, dentro do conteúdo programático, aborde-se: "as causas de contaminação dos alimentos, prevenção e eliminação das mesmas".

Oliveira; Gonçalves, Shinohara e Stamford (2003) ratificam que educação higiênicosanitária para manipuladores reduz significativamente os perigos de contaminação dos alimentos, o que não descarta a necessidade de treiná-los continuamente. E que manipuladores de alimentos com sintomas de "diarréias, febre, resfriado, sinusite, faringite ou lesões cutâneas, principalmente nas mãos" devem ser desviados de suas atividades até sua reabilitação.

O programa de educação continuada, tem como objetivo o comprometimento dos manipuladores de alimentos, gerando pelas mudanças propostas pelo treinamento. Esta educação continuada favorece "a inclusão dos indivíduos em processos de ensinoaprendizagem, voltados prioritariamente para as atividades profissionais, visando a reciclagem e ampliação dos conteúdos" (Silva, Germano e Germano, 2003). 
Os autores apontam os "programas de treinamentos específicos para manipuladores de alimentos como a maneira mais eficaz para transferir conhecimento e originar mudanças comportamentais". Porém, ressaltam que a maioria dos manipuladores de alimentos possui "baixa escolaridade, dificuldade para ler e escrever, e até em se expressar verbalmente". Para tornar o treinamento eficaz, os autores sugerem:

- $\quad$ a apresentação dos objetivos do treinamento com clareza;

- $\quad$ o conhecimento prévio do público alvo;

- a aplicação de estratégias de ensino adequadas para favorecer o aprendizado;

- $\quad$ o emprego de linguagem adequada que facilite o entendimento;

- o uso da criatividade pelo corpo docente para evitar métodos repetitivos de ensino;

- $\quad$ o uso de técnicas de reforço para manutenção dos conceitos desenvolvidos;

- o compromisso de apresentar ao grupo os resultados obtidos, discutindo as possíveis falhas e buscando novas formas de aperfeiçoamento

Silva, Germano e Germano (2003), enfatizam a importância de tratar da saúde dos manipuladores de alimentos, através de exames médicos e laboratoriais periódicos.

As superfícies empregadas na preparação dos alimentos e utensílios podem transformarse em "focos de contaminação", principalmente se não forem bem higienizados. Os resíduos orgânicos deixados, devido a má higienização, nutrem microrganismos, como fungos e bactérias, formando biofilmes. A lavagem correta com água e sabão reduz os resíduos orgânicos nas superfícies, e os produtos desinfetantes e o calor, reduzem os microrganismos deteriorantes e patogênicos a níveis aceitáveis, minimizando e dificultando a formação de biofilmes (Silva Junior, 2001).

\subsection{O Sistema de AnÁlise de Perigos e Pontos Críticos de Controle}

O Sistema APPCC está designado para ser implantado em toda a cadeia produtiva: “produção primária, transformação, transporte, distribuição, armazenamento, exposição à venda, consumo ou qualquer outra etapa que represente risco ao produto”. Envolvendo produtores primários, indústrias, consumidores, transportadores, fiscalizadores/inspetores, 
importadores/exportadores e os fornecedores de produtos e serviços de qualquer natureza que se relacione com o produto: “embalagens, rotulagem, agentes de limpeza e desinfecção, fornecedores de equipamentos, engenheiros projetistas de áreas físicas e de equipamentos, agências de controle de insetos e roedores, manipuladores de alimentos, funcionários da empresa, trabalhadores rurais e outros, de forma a identificar, caracterizar, adotar medidas preventivas de controle e efetivamente controlar os perigos possíveis dos produtos alimentícios” (Silva Júnior, 2001).

Nas indústrias de alimentos, o APPCC é uma técnica conhecida para analisar perigos em operação, identificar onde eles podem ocorrer e decidir quais são críticos para a segurança do consumidor. Tais perigos podem ser físicos, químicos ou microbiológicos, podendo ocorrer em qualquer estágio do processamento, da matéria-prima até ao consumo. É um sistema dinâmico para o controle dos perigos, pois a segurança é oferecida por esses controles, e não pela análise do produto final. Proporciona as seguintes vantagens: "é preventivo; mediante o enfoque dinâmico na cadeia de produção; garante a segurança e qualidade; reduz custos, já que minimiza as perdas e o retrabalho; incrementa a produtividade e competitividade; atende as exigências dos mercados internacionais” (Makiya e Rotondaro, 2002).

Os mesmos autores informam que "órgãos relacionados à Saúde Pública e os governos de diversos países, principalmente Estados Unidos e a Comunidade Européia, têm buscado formas de garantir a segurança dos alimentos, através do monitoramento de suas cadeias produtivas".

Castro; Schimidt e Leitão (2002) esclarecem que o APPCC é um sistema que consiste fundamentalmente das seguintes etapas: identificação das operações nas quais os alimentos podem ser contaminados; determinação se os patógenos e outros contaminantes sobreviverão ou não ao processamento e determinação das oportunidades que possibilitem a multiplicação destes patógenos a um nível que coloque a saúde do consumidor em risco; identificação dos pontos críticos de controle das operações; implementação de um controle apropriado e das medidas preventivas; monitoramento, rotineiro, das operações em cada ponto crítico de controle. 
Almeida (2002) menciona que todos os agentes da cadeia produtiva, citados anteriormente, devem receber informações sobre os alimentos e seus procedimentos para poderem localizar fontes e formas de contaminação, e para identificar as suas medidas preventivas, tornando as análises laboratoriais e as inspeções inúteis. Tal autor complementa que o APPCC é um método sistematizado científico e tecnológico para "planejar, controlar e documentar a produção segura de alimentos".

Almeida (2002) destaca que os perigos potenciais à inocuidade dos alimentos, são: químicos, físicos e biológicos, sendo que os perigos químicos (como os agrotóxicos) são os mais "temidos pelos consumidores", os perigos físicos (material estranho, pêlos, fragmentos de ossos, metais ou vidros), como sendo os mais facilmente reconhecidos e os perigos biológicos como os mais sérios, do ponto de vista da saúde pública, e devem ser abordados com mais detalhes no plano APPCC.

Almeida (2002) ressalta que as instalações de processamento de alimentos compõem um local muito apropriado para a adoção do APPCC, e reconhece que o treinamento é fundamental para sua implementação adequada. E recomenda que os materiais educativos como o manual de Boas Práticas de Fabricação devem atingir também os manipuladores de alimentos domésticos.

Silva-Júnior (2001) diz que o maior desafio é o treinamento e capacitação do pessoal neste sistema, e que é importante ressaltar que não se pode, sob nenhuma hipótese, desconsiderar os princípios e as regras das Boas Práticas de Fabricação na conceituação e implementação do Sistema APPCC, e afirma que, quando as Boas Práticas de Fabricação não são respeitadas, não existe maneira e nem motivos para implementar o APPCC.

\subsection{BoAs PRÁtiCAS DE FABRICAÇÃo E PROCEDIMENTOS OPERACIONAIS PADRONIZAdOS}

As Boas Práticas de Fabricação (BPF's) são requisitos fundamentais para a redução dos pontos críticos de controle, sendo o princípio higiênico-sanitário para implantação do sistema APPCC. As BPF's contemplam desde projetos de prédios e instalações, manutenção, planos de higiene pessoal e sanificação dos processos, transporte da matéria prima e insumos, produtos químicos e acabados, informações ao consumidor via rotulagem dos alimentos, 
controle integrado de pragas e treinamento/reciclagem de funcionários, abordando condições de armazenamento e distribuição (Nassau; Benevides; Borges; Silva e Andrade, 2003).

Silva Junior (2001) considera que o APPCC é um sistema que pode ser aplicado em qualquer etapa de um processo e enfatiza que este sistema abrange todas as regras das Boas Práticas de Fabricação e Procedimentos Operacionais Padronizados. Assim, o mesmo autor explica que as BPF's são pré-requisitos para implementação do APPCC.

O mesmo autor explica ainda que o manual de boas práticas de fabricação deve contemplar todos os procedimentos operacionais que envolvam as atividades da área de produção, aspectos de higiene pessoal, alimentar e ambiental. Além disso, deve-se enfocar os procedimentos relacionados com a aquisição de mercadorias e matéria-prima, pré-requisitos de fornecedores, recebimento, estocagem, pré-processamento, processamento, acondicionamento, transporte, distribuição, e manutenção predial e dos equipamentos. Enfatiza ainda, que após a implantação do manual de BPF's, a sensibilização dos dirigentes e dos colaboradores da empresa é uma das etapas mais importantes para o sucesso na implantação do APPCC. 


\section{Material e Métodos}

Para a realização deste estudo fez-se um estudo analítico em um entreposto de mel e cera de abelhas localizado no Entorno do Distrito Federal, na cidade de Águas Lindas, Goiás. A seleção do local foi não aleatória, uma vez a pesquisadora atuou nesse estabelecimento como gerenciadora da produção e da qualidade durante cinco anos.

Como metodologia para o desenvolvimento do sistema APPCC, fez-se uma descrição detalhada do mel, método de distribuição, possibilidades de agressões ao produto durante sua distribuição, venda no varejo, consumo. Para o plano de Análise de Perigos e Pontos Críticos de Controle foram efetuadas adaptações dos métodos preconizados pelo Senai, por meio do documento Elementos de apoio para o sistema APPCC, e do Manual genérico de procedimentos para APPCC em indústrias de produtos de origem animal do Ministério da Agricultura (Brasil, 1998):

- foram identificados o uso pretendido e consumidores do mel (formulário D);

- foi construído, um diagrama operacional e sua verificação prática: este diagrama contempla todas as etapas do produto, de forma seqüencial, clara e simples. O objetivo foi indicar a direção seguida pelo mel. Este diagrama está acompanhado da descrição do processo (formulário $\mathrm{F}$ );

- após estabelecimento do diagrama operacional foi efetuada uma inspeção no local, para verificar a concordância das operações descritas com o que foi representado;

- foram listados e identificados os perigos biológicos (formulário G), os perigos físicos (formulário H) e os químicos (formulário I). Além da análise de riscos, foram levantadas as medidas preventivas de controle;

- a análise dos riscos envolveu a listagem e identificação dos perigos que podiam ocorrer em toda a cadeia produtiva, além das medidas preventivas de controle (desde a aquisição da matéria-prima até o produto final);

- todos os perigos levantados, associados a cada etapa de produção, tiveram sua severidade avaliada. Os riscos foram avaliados em relação à sua importância para a saúde pública (considerada a ligação epidemiológica do produto em análise com enfermidades transmitidas por alimentos - ETAs), à perda da qualidade do mel (deterioração, grau de frescura) e sua integridade econômica (adição de água, adição de sacarose, aumento de 
peso por adição de algum elemento em detrimento de sua composição normal ou de valor nutritivo intrínseco);

- os riscos foram avaliados e buscou-se a sua prevenção, redução a níveis aceitáveis ou eliminação total;

- identificaram-se os Pontos Críticos de Controle (PCCs) e a aplicação da árvore decisória, na qual se fizeram algumas perguntas para cada etapa de elaboração do produto (formulário M);

- os perigos que não eram controlados no estabelecimento foram listados e identificados (formulário J);

- estabeleceram-se limites críticos para cada ponto crítico de controle. Os limites críticos são os valores que separam os produtos aceitáveis dos inaceitáveis; são qualitativos e/ou quantitativos (tempo, temperatura, $\mathrm{pH}$, umidade, atividade de água, viscosidade, aroma e sabor);

- estabeleceu-se o sistema de monitorização para cada PCC buscando detectar qualquer desvio do processo ou perda de controle com tempo suficiente para que as medidas corretivas fossem adotadas antes da distribuição do produto (formulário N);

- estabeleceram-se as ações corretivas: elas serão tomadas quando se constatar algum desvio nos limites críticos estabelecidos, colocando os PCCs novamente sob controle (exemplo: rejeitar a matéria-prima, reprocessar).

O plano APPCC está apresentado nos formulários a seguir . 


\section{FORMULÁRIO A}

IDENTIFICAÇÃO DA EMPRESA

RAZÃo SociAL: Entreposto Apícola da Barragem Ltda.

ENDEREÇO: BR 070 Km 02 Fazenda Cachoeira, s/nº

CEP 72910-000

CiDADE: Águas Lindas

ESTADO: Goiás

TELEFONE: 0616186083

FAX: 0616185356

CNPJ.: 37.006.517/0001-06

IE.: 1.023.4033-1

RESPONSÁVEL TÉCNICO: Lilian Osachlo

Nº DE REGISTRO NO SIF: 739

CATEgoria do Estabelecimento: Entreposto de Mel e Cera de Abelhas

\section{RELAÇÃO DOS PRODUTOS ELABORADOS:}

- Mel

- Mel composto

- Extrato de própolis

Destino da Produção: Mercado Nacional 
FORMULÁRIO B

ORGANOGRAMA DA EMPRESA

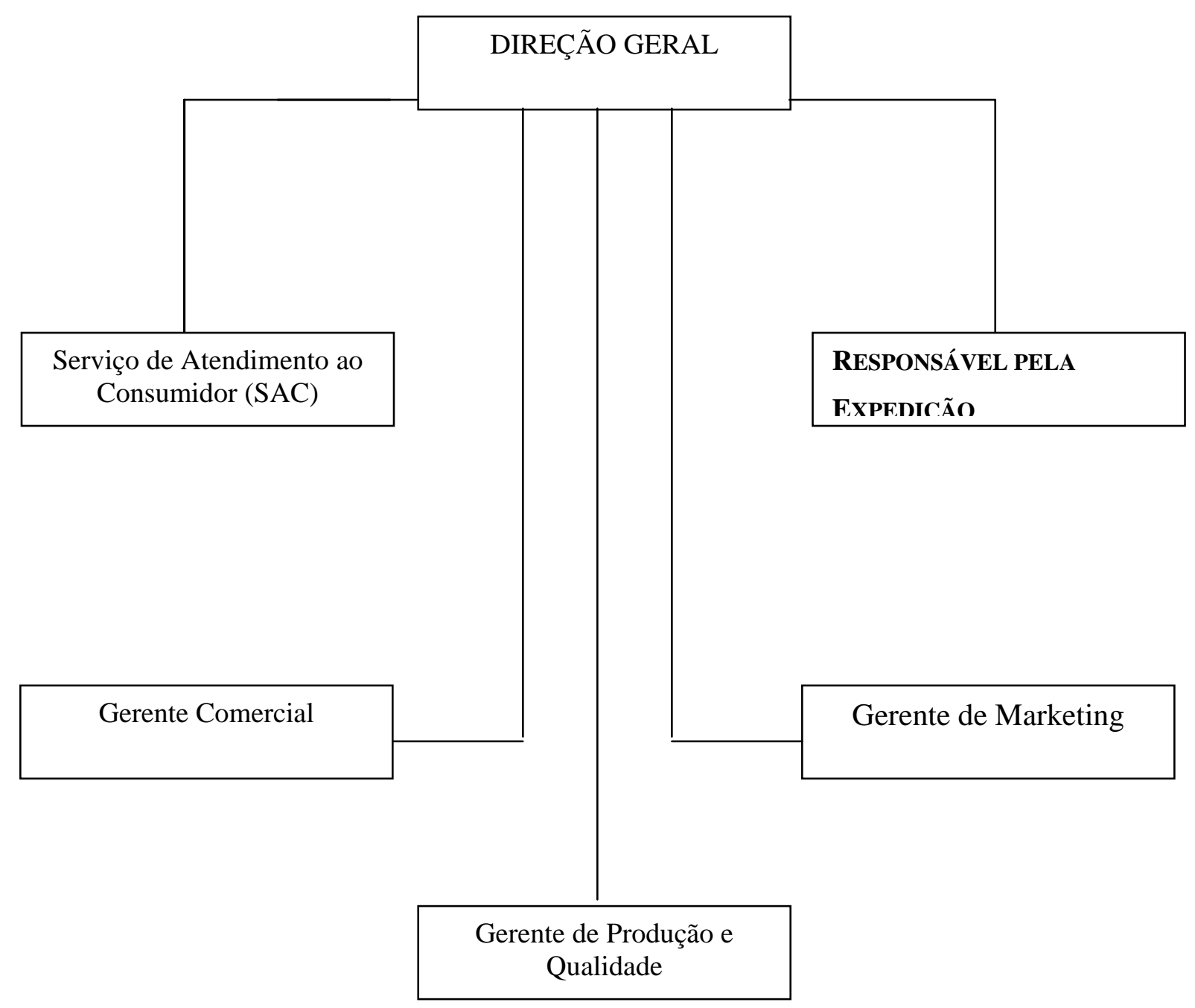




\section{FORMULÁRIO C}

EQUIPE APPCC

\begin{tabular}{|c|c||}
\hline Nome & Função \\
\hline Lilian Osachlo & Coordenador do APPCC \\
\hline Odir Oliveira & Supervisora do APPCC \\
\hline Francisco de Assis Sobrinho & Monitor do APPCC \\
\hline Tatiana Valéria Reis & Secretário do APPCC \\
\hline
\end{tabular}


FORMULÁRIO D

DESCRIÇ̃̃O DO PRODUTO

\section{- Nome do Produto:}

Mel

- Características importantes do produto final:

- $\mathrm{pH}: 3,6$ a 4,2

- $\mathrm{A}_{\mathrm{W}:}: 0,60$

- Formas de uso do produto pelo consumidor:

Consumido diretamente, utilizado em frutas, cereais, sucos, como adoçante ou na culinária em pratos quentes (bolos, pães, crepes, panquecas e assados) ou frios como saladas.

- Características da embalagem:

Frascos para 250 g, 300 g, 450 g e 1000 g.

- Local de Venda do Produto:

Supermercados, hipermercados, padarias, lojas de conveniência, farmácias e drogarias

- Prazo de validade:

2 anos.

- Composição do produto:

Mel

- Instruções contidas no rótulo:

Manter em local fresco. O mel puro pode cristalizar com o tempo, podendo ser consumido nesta forma cremosa. Porém, se desejar, o mel pode voltar ao seu estado original, bastando para isso, colocar o frasco em banho-maria sem ferver $\left(50^{\circ} \mathrm{C}\right.$ por 30 minutos)

- Controles especiais durante distribuição e comercialização:

No transporte, evitar choques e exposição a altas temperaturas 
FORMULÁRIO E

COMPOSIÇÃO DO PRODUTO

\begin{tabular}{|c|c|c||}
\hline Matéria-prima & Ingredientes secos & Ingredientes líquidos \\
\hline Mel & --- & --- \\
\hline ---- & Aromatizantes & Conservadores \\
\hline Outros ingredientes & --- & \\
\hline $\begin{array}{l}\text { Material da embalagem } \\
\text { Vidros, rótulos, lacres de } \\
\text { PVC, caixas de papelão } \\
\text { ondulado }\end{array}$ & & \\
\hline \begin{tabular}{l} 
Lado \\
\hline
\end{tabular} & & \\
\hline
\end{tabular}




\section{FORMULÁRIO F}

FLUXOGRAMA E DESCRIÇÃO DO PROCESSO

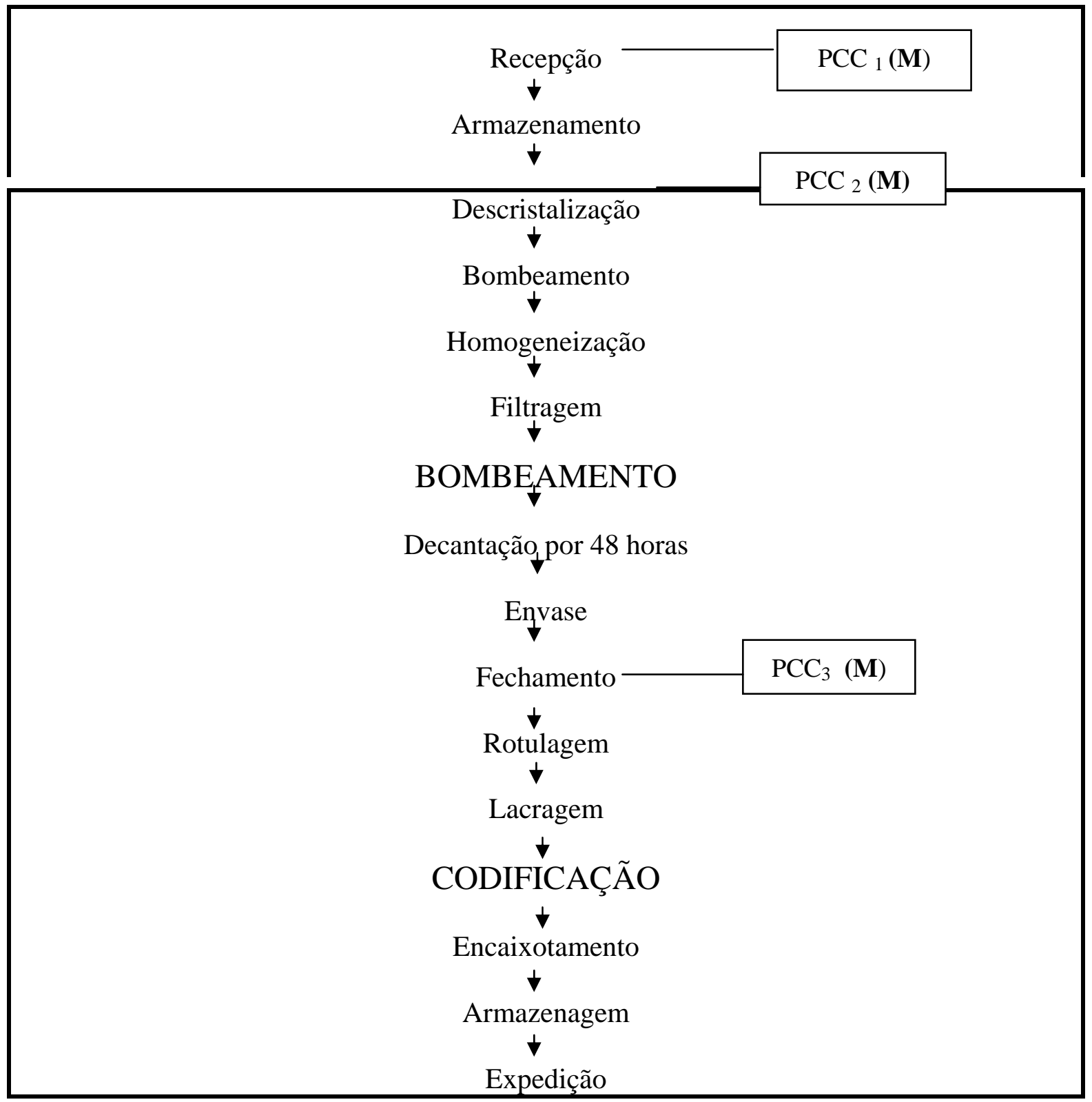




\section{FORMULÁRIO F}

DESCRIÇÃO DE PROCESSO

\section{RECEPÇÃO DE MATÉRIAS-PRIMAS}

- Horário de funcionamento: 07:00 às 17:00 - segunda-feira a sexta-feira

São recebidos méis:

- maduros, desorpeculados e centrifugados;

- de fornecedores cadastrados com certificado de qualidade e laudo de análise emitido em laboratório confiável;

- acondicionados em embalagens bromatológicamente aptas (lata de flandres, baldes plásticos, tambores e/ou bombonas), em boas condições (sem amassados, ferrugens, furos ou sujeiras);

No momento da descarga:

1. identificar corretamente as embalagens e registrar em planilhas próprias;

2. coletar amostras, aleatoriamente, para avaliação das características organolépticas (cor, aroma, consistência e sabor),

3. a carga é recebida após a avaliação e aprovação do produto, os méis devem corresponder aos padrões estabelecidos no momento da aquisição, conforme ordem de compra. Não são aceitos méis com problemas de fermentação e adulteração de qualidade (por exemplo: acréscimo de água);

4. a umidade é medida imediatamente na recepção através do método Brix refratômetro manual, sendo a tolerância máxima de umidade aceita de 20\%;

5. não são ressarcidos custos no tocante a frete, impostos ou custos relativos a matéria-prima fora dos padrões estipulados;

6. o pagamento é efetuado após a certificação de qualidade da matéria-prima. 


\section{ArmazenAmento de MATÉRIAS-PRimas}

- A matéria-prima, devidamente identificada, é armazenada em paletes apropriados, localizados no depósito de matéria-prima, conforme Instrução de Trabalho (I.T) de armazenamento;

- é respeitada a instrução "Primeiro que Entra é Primeiro que Sai (PEPS)";

- as latas são limpas com água e sabão, e secas antes do armazenamento, conforme descrito na Instrução de Trabalho de Armazenamento.

\section{DESCRISTALIZAÇÃO}

- Verificar a programação;

- pesar as latas;

- anotar mescla e pesos das latas na planilha de processamento;

- acomodar as latas tampadas no descristalizador e preencher o equipamento com água até uma altura suficiente para garantir uniformidade da temperatura interna do mel.

- abrir as latas;

- anotar as condições do mel na planilha de processamento (aparência e umidade);

- méis que apresentem quaisquer fragmentos (abelhas, cera ou gravetos) são previamente limpos antes do seu processamento, conforme descrito no Procedimento Operacional Padrão (POP) de processamento.

- medir a temperatura interna do mel;

- monitorar a temperatura a cada 60 minutos até completar, aproximadamente, seis horas de processamento e garantindo a temperatura interna, mínima, de $63^{\circ} \mathrm{C}$ e máxima de $65^{\circ} \mathrm{C}$;

- anotar as temperaturas mensuradas na planilha de processamento;

- homogeneizar o produto com o auxílio de uma pá de aço inox, plástica ou nylon, previamente higienizada (conforme POP de higienização de superfícies em contato com o produto);

\section{HoMOgENEIZAÇÃo E Mistura}

Após descristalização completa do mel: 
1. Bombear o mel das latas para o homogeneizador,previamente limpo e higienizado, através da bomba peristáltica;

2. fechar a tampa do equipamento;

3. ligar as pás giratórias e homogeneizar o mel por 30 (trinta) minutos;

4. medir a temperatura do mel, o mel é filtrado a uma temperatura entre $50^{\circ}$ e $38^{\circ} \mathrm{C}$,

5. ligar a bomba peristáltica, que deverá estar acoplada da saída do equipamento ao filtro, com elemento filtrante de nylon, poliéster ou polipropileno com malha de 100 micras;

6. acomodar a mangueira de saída do filtro ao decantador de aço inox, previamente limpo e higienizado, o mel deverá escorrer pelas paredes do decantador, a fim de evitar formação de bolhas de ar, indesejáveis ao produto;

7. anotar o número do decantador na planilha de processamento;

8. descartar as embalagens latas vazias, pós-processamento (conforme o POP descarte de embalagens).

\section{DECANTAÇÃo}

- Após o bombeamento, o mel "descansa" no decantador por 48 horas antes do envase;

- após decantação completa, forma-se uma espuma superficial que é retirada com o auxílio de espátula tipo "pão-duro", e descartada (conforme POP envase).

\section{ENVASE E FECHAMENTO}

- verificar a programação do envase;

- solicitar as embalagens (frascos e tampas) ao almoxarifado;

- conferir as embalagens solicitadas e os acessórios necessários para o envase (espátula tipo "pão-duro", papel toalha, balança), previamente higienizados;

- soprar os frascos e tampas direcionando o ar comprimido para o lado oposto dos frascos já soprados;

- inspecionar visualmente os frascos e tampas, e iniciar o envase, rejeitando os frascos quebrados, trincados ou sujos;

- acomodar os frascos na bancada de cabeça para baixo próximos ao envasador; 
- posicionar o frasco sob o bico dosador da envasadeira previamente higienizada, conforme POP sanitização;

- tarar a balança, previamente limpa e sanitizada, colocando o frasco vazio sobre a mesma;

- iniciar o envase (Conforme descrito no POP envase), respeitando a gramatura adequada com tolerância conforme CEP (Controle Estatístico do Processo);

- fechar adequadamente o frasco imediatamente após o envase;

- acomodar os frascos envasados em caixotes plásticos e paletizados;

- etiquetar os caixotes com florada, data de embalagem e lote, transferido-os para área de acabamento;

- repetir o processo até esgotamento do decantador, anotar a quantidade envasada na planilha de processamento

\section{RoTULAGEM}

- Antes de iniciar as tarefas, proceder à limpeza do setor de acabamento, conforme POP de sanitização e limpeza;

- os frascos são rotulados em rotuladeira semi-automática, conforme descrito no POP de Acabamento (a rotuladeira tem manutenção preventiva periódica, de acordo com o POP de Manutenção e Calibração de Equipamentos).

\section{CODIFICAÇÃo}

- antes de iniciar as tarefas, proceder à limpeza do setor, conforme POP de sanitização e limpeza.

- a codificação a jato de tinta é feita na tampa do produto, codificando a data de embalagem, data de validade e número do lote.

\section{SELAGEM}

- os frascos rotulados recebem lacre de PVC termo-encolhível, colocados manualmente pelos funcionários do acabamento;

- os frascos com lacre seguem para uma esteira interligada a um túnel de encolhimento, que joga ar quente $\left(200^{\circ} \mathrm{C}\right)$, pelas laterais do frasco encolhendo o lacre de pvc;

- estes frascos seguem para uma mesa acumuladora giratória, onde um funcionário encaixota-os.

\section{ENCAIXOTAMENTO}

- os produtos são colocados em caixas de papelão adequadas, onde recebem, internamente, um selo de garantia de qualidade; 
- as caixas são fechadas com fita adesiva, recebem etiquetas externas, com a mesma codificação do frasco (florada, data de embalagem, validade e lote).

\section{Armazenamento}

- Paletizam-se as caixas por gramatura, florada e data . Para organizar a saída de produtos usa-se o sistema Primeiro que Entra é Primeiro que Sai (PEPS), conforme descrito na I.T de armazenamento. 
Formulário G

IDENTIFICAÇÃO DOS PERIGOS

PERIGOS BIOLÓGICOS

\begin{tabular}{|c|c|c|c|c|c|}
\hline $\begin{array}{l}\text { Ingredientes/ Etapa } \\
\text { de Processo }\end{array}$ & $\begin{array}{l}\text { Perigo } \\
\text { Biológico }\end{array}$ & JUSTIFICATIVA & $\begin{array}{l}\text { Severi- } \\
\text { dade }\end{array}$ & Risco & Medidas Preventivas \\
\hline Recepção do Mel & $\begin{array}{c}\text { Esporos de } \underline{\text { Clostridium }} \\
\underline{\text { botulinum }}\end{array}$ & Microbiota Natural & Alta & Baixo & $\begin{array}{l}\text { BPFs no fornecedor } \\
\text { (qualificação) e Laudo de Análise } \\
\text { na aquisição }\end{array}$ \\
\hline Armazenamento & $\begin{array}{l}\text { Esporos de Clostridium } \\
\text { botulinum,e de outras } \\
\text { bactérias patógenas }\end{array}$ & Microbiota Natural & Alta & Baixo & BPFs \\
\hline Descristalização & $\begin{array}{c}\text { Esporos de } \underline{\text { C.botulinum }} \\
\text { Enterobactérias patogênicas } \\
\text { e } \underline{\text { S. aureus }}\end{array}$ & $\begin{array}{l}\text { Microbiota Natural - } \\
\text { Manuseio do produto }\end{array}$ & Alta & Médio & $\begin{array}{l}\text { BPFs } \\
\text { POP Pessoal e processo } \\
\text { Controle de } \mathrm{pH} \text {, oxigênio e } A_{W}\end{array}$ \\
\hline Envase & $\begin{array}{l}\text { Recontaminação por } \\
\text { Enterobactérias patogênicas } \\
\text { e } \underline{\text { Staphylococcus aureus }}\end{array}$ & $\begin{array}{l}\text { Falhas nos procedimentos } \\
\text { higiênico-sanitários } \\
\text { provocarão multiplicação de } \\
\text { patógenos }\end{array}$ & Média & Médio & $\begin{array}{l}\text { BPFs: pessoal, equipamentos, } \\
\text { instalações e treinamento } \\
\text { operacional } \\
\text { Controle de portadores } \\
\text { assintomáticos } \\
\text { Treinamento de pessoal }\end{array}$ \\
\hline Fechamento & $\begin{array}{c}\text { Esporos de } \underline{\text { C.botulinum }} \\
\text { Recontaminação } \\
\text { por microrganismos } \\
\text { patogênicos }\end{array}$ & $\begin{array}{l}\text { Falhas nos procedimentos } \\
\text { Higiênico-sanitários ou manuten- } \\
\text { ção do frasco,aberto por período } \\
\text { prolongado, podem levar à } \\
\text { contaminação e multiplicação } \\
\text { de microrganismos patogênicos } \\
\text { que podem afetar a saúde do } \\
\text { consumidor . }\end{array}$ & Média & Médio & $\begin{array}{l}\text { BPFs: pessoal, equipamentos, } \\
\text { instalações e treinamento } \\
\text { operacional. Controle de } \\
\text { portadores assintomáticos }\end{array}$ \\
\hline
\end{tabular}


FORMULÁRIO H

Identificação dos perigos

PERIGOS FÍSICOS

\begin{tabular}{|c|c|c|c|c|c|}
\hline $\begin{array}{l}\text { INGREDIENTES/ } \\
\text { ETAPA DE } \\
\text { PROCESSO }\end{array}$ & $\begin{array}{l}\text { PERIGO } \\
\text { FÍSICO }\end{array}$ & Justificativa & $\begin{array}{l}\text { SEVERI- } \\
\text { DADE }\end{array}$ & RISCO & "MEDIDAS PREVENTIVAS \\
\hline Armazenagem & $\begin{array}{l}\text { Fragmentos de abelhas ou de } \\
\text { outros insetos, madeira, } \\
\text { metal, cera e vidro }\end{array}$ & $\begin{array}{l}\text { Ingrediente pode conter } \\
\text { fragmentos da origem }\end{array}$ & Baixa & Baixa & $\begin{array}{l}\text { Programa de qualificação e seleção de } \\
\text { fornecedores } \\
\text { BPFs no fornecedor } \\
\text { Avaliação no recebimento }\end{array}$ \\
\hline Decantação & $\begin{array}{l}\text { Fragmentos ou presença de } \\
\text { insetos }\end{array}$ & $\begin{array}{l}\text { Ingrediente pode atrair } \\
\text { insetos }\end{array}$ & Média & Baixo & POP de Controle de vetores e pragas \\
\hline
\end{tabular}


FORMULÁRIO I

ANÁLISE DOS PERIGOS

PERIGOS Químicos

\begin{tabular}{|c|c|c|c|c|c|}
\hline $\begin{array}{l}\text { INGREDIENTES/ } \\
\text { ETAPA DE } \\
\text { PROCESSO } \\
\end{array}$ & $\begin{array}{c}\text { PERIGO } \\
\text { QUÍMICO }\end{array}$ & Justificativa & $\begin{array}{c}\text { SEVERI } \\
\text { DADE }\end{array}$ & RISCO & MEDIDAS PREVENTIVAS \\
\hline $\begin{array}{l}\text { Armazenamento } \\
\text { de matéria-prima, } \\
\text { insumos e } \\
\text { embalagens }\end{array}$ & $\begin{array}{l}\text { Resíduos de } \\
\text { produtos químicos, } \\
\text { graxas, } \\
\text { lubrificantes, } \\
\text { produtos de } \\
\text { limpeza, } \\
\text { inseticidas }\end{array}$ & $\begin{array}{l}\text { Armazenamento de produtos químicos no } \\
\text { mesmo depósito de embalagens e insumos } \\
\text { podem contaminá-los; } \\
\text { Contaminação na origem. }\end{array}$ & Baixa & Alto & $\begin{array}{ll}\text { - } & \text { BPFs } \\
\text { - } & \text { Armazenamento em } \\
\text { - } & \text { locais separados } \\
\text { - } & \text { Treinamento de pessoal } \\
\text { - } & \text { Programa de qualificação e } \\
& \text { seleção de fornecedores. } \\
\text { - } & \text { Avaliação na recepção da } \\
& \text { matéria-prima } \\
\end{array}$ \\
\hline Descristalização & $\begin{array}{l}\text { Entrada de água } \\
\text { do descristalizador } \\
\text { no mel }\end{array}$ & $\begin{array}{l}\text { Contaminação de origem; } \\
\text { Manipulação inadequada dos baldes pode levar } \\
\text { respingar e/ou derramar água no mel }\end{array}$ & Baixa & Baixo & $\begin{array}{ll}\text { - } & \text { BPFs } \\
\text { - } & \text { Treinamento de pessoal }\end{array}$ \\
\hline Homogeneização & $\begin{array}{l}\text { Resíduos de } \\
\text { detergentes }\end{array}$ & $\begin{array}{l}\text { Enxágüe malfeito, durante a higienização do } \\
\text { Equipamento pode deixar resíduos que } \\
\text { contaminarão o } \\
\text { produto podendo intoxicar o consumidor }\end{array}$ & Média & Baixo & $\begin{array}{ll}\text { - } & \text { BPFs } \\
\text { - } & \text { Treinamento de pessoal } \\
\text { - } & \text { Inspeção do equipamento após } \\
& \text { a limpeza } \\
\text { - } & \text { Uso de materiais adequados } \\
& \text { nos equipamentos (aço inox) } \\
\end{array}$ \\
\hline Decantação & $\begin{array}{l}\text { Resíduos de } \\
\text { detergentes }\end{array}$ & $\begin{array}{l}\text { Enxágüe malfeito, durante a higienização do } \\
\text { Equipamento pode deixar resíduos que } \\
\text { contaminarão o produto podendo intoxicar } \\
\text { o consumidor }\end{array}$ & Média & Baixo & $\begin{array}{ll}\text { - } & \text { BPFs } \\
\text { - } & \text { Treinamento do pessoal } \\
\text { - } & \text { Inspeção do equipamento } \\
& \text { pós-limpeza } \\
\end{array}$ \\
\hline
\end{tabular}


FORMULÁRIO J

QUADRO DE PERIGOS QUE NÃO SÃO CONTROLADOS NO ESTABELECIMENTO

(PRODUTO ACABADO)

Nome do Produto: Mel

\begin{tabular}{||l|l||}
\hline \multicolumn{1}{|c||}{$\begin{array}{c}\text { PERIGOS IDENTIFICADOS RELATIVOS A FONTES } \\
\text { EXTERNAS AO ESTABELECIMENTO }\end{array}$} & $\begin{array}{c}\text { MEDIDAS PREVENTIVAS } \\
\text { (INSTRUÇÕES AO CONSUMIDOR) }\end{array}$ \\
\hline & $\begin{array}{l}\text { Medidas de conscientização quanto à conservação e uso do alimento, } \\
\text { na rotulagem. } \\
\text { Recontaminação e multiplicação por microrganismos patogênicos na } \\
\text { casa do consumidor. }\end{array}$ \\
\hline \hline
\end{tabular}


FORMULÁRIO L

IDENTIFICAÇÃO DE MATÉRIA-PRIMA/ INGREDIENTE CRÍTICO

NOME DO PRODUTO: Mel

\begin{tabular}{||l|l|c|c|c||}
\hline \multicolumn{1}{|c||}{$\begin{array}{c}\text { Matéria-prima/ } \\
\text { Ingrediente }\end{array}$} & $\begin{array}{l}\text { Perigos identificados e } \\
\text { categoria (biológicos, químicos } \\
\text { e/ou físicos) }\end{array}$ & $\begin{array}{c}\text { Questão 1: } \\
\text { O perigo pode ocorrer em } \\
\text { níveis inaceitáveis? }\end{array}$ & $\begin{array}{c}\text { Questão 2: } \\
\text { O processo ou o consumidor } \\
\text { eliminará ou reduzirá o perigo } \\
\text { a um nível aceitável? }\end{array}$ \\
\hline Mel & $\begin{array}{l}\text { Biológico: } \\
\text { Esporos de microrganismos } \\
\text { patogênicos : } \\
\text { Clostridium botulinum }\end{array}$ & Sim & Não \\
\hline Mel & $\begin{array}{l}\text { Físico: } \\
\text { Fragmentos de metais, insetos, } \\
\text { vidros, madeira }\end{array}$ & Sim & Sim \\
\hline Mel & $\begin{array}{l}\text { Quítico (C) } \\
\text { de limpeza }\end{array}$ & Sim & Sim \\
\hline
\end{tabular}




\section{FORMULÁRIO M}

DETERMINAÇÃO DO PCC

NOME DO PRODUTO: MEL

\begin{tabular}{|c|c|c|c|c|c|c|c|}
\hline $\begin{array}{l}\text { Etapa do } \\
\text { Processo }\end{array}$ & $\begin{array}{c}\text { Perigos } \\
\text { Significativos } \\
\text { (biológicos, químicos } \\
\text { e físicos) }\end{array}$ & $\begin{array}{l}\text { O perigo é } \\
\text { controlado } \\
\text { pelo } \\
\text { programa de } \\
\text { pré- } \\
\text { requisitos? }\end{array}$ & $\begin{array}{c}\text { Questão 1 } \\
\text { Existem } \\
\text { medidas } \\
\text { preventivas para } \\
\text { o perigo? }\end{array}$ & $\begin{array}{c}\text { Questão 2 } \\
\text { Esta etapa } \\
\text { elimina ou reduz } \\
\text { o perigo a níveis } \\
\text { aceitáveis? }\end{array}$ & $\begin{array}{c}\text { Questão } 3 \\
\\
\text { O perigo pode } \\
\text { aumentar a níveis } \\
\text { inaceitáveis? }\end{array}$ & $\begin{array}{c}\text { Questão 4 } \\
\\
\text { Um a etapa } \\
\text { subseqüente } \\
\text { eliminará ou } \\
\text { reduzirá o perigo a } \\
\text { níveis aceitáveis? }\end{array}$ & PCC \\
\hline \multirow{3}{*}{$\begin{array}{l}\text { Recepção/ } \\
\text { Armazenamento }\end{array}$} & $\begin{array}{l}\text { Biológicos: Esporos } \\
\text { de } \underline{\text { C. botulinum }}\end{array}$ & Sim & Sim & Sim & Sim & Não & $\mathrm{PCC}_{1}(\mathrm{M})$ \\
\hline & $\begin{array}{l}\text { Químicos: Resíduos } \\
\text { de produtos de } \\
\text { limpeza, água da } \\
\text { origem da Matéria } \\
\text { prima }\end{array}$ & Sim & Sim & Sim & Não & Sim & PC \\
\hline & $\begin{array}{l}\text { Físicos: fragmentos } \\
\text { de madeira e metais }\end{array}$ & Sim & Sim & Sim & Não & Sim & PC \\
\hline
\end{tabular}

Continua... 
FORMULÁRIO M

DETERMINAÇÃO DO PCC

NOME DO PRODUTO: MEL

\begin{tabular}{|c|c|c|c|c|c|c|c|}
\hline $\begin{array}{l}\text { Etapa do } \\
\text { processo }\end{array}$ & $\begin{array}{l}\text { Perigos significativos } \\
\text { (biológicos, químicos } \\
\text { e físicos) }\end{array}$ & $\begin{array}{c}\text { O perigo é } \\
\text { controlado } \\
\text { pelo programa } \\
\text { de pré- } \\
\text { requisitos }\end{array}$ & $\begin{array}{c}\text { Questão 1 } \\
\text { Existem } \\
\text { medidas } \\
\text { preventivas para } \\
\text { o perigo? }\end{array}$ & $\begin{array}{c}\text { Questão } 2 \\
\text { Esta etapa reduz o } \\
\text { perigo a niveis } \\
\text { aceitáveis }\end{array}$ & $\begin{array}{c}\text { Questão } 3 \\
\\
\text { O perigo pode } \\
\text { aumentar a níveis } \\
\text { inaceitáveis? }\end{array}$ & $\begin{array}{c}\text { Questão 4 } \\
\text { Uma etapa } \\
\text { subsequente } \\
\text { eliminará ou } \\
\text { reduzirá o perrigo a } \\
\text { níveis aceitáveis? }\end{array}$ & PCC \\
\hline \multirow[t]{3}{*}{ Descristalização } & $\begin{array}{ll}\text { Biológicos: } & \text { Esporos } \\
\text { Clostridium } & \\
\underline{\text { botulinum }} & \end{array}$ & Sim & Sim & Sim & Sim & Não & $\begin{array}{c}\text { PCC }_{2} \\
(\mathrm{M})\end{array}$ \\
\hline & $\begin{array}{l}\text { Químicos: água de } \\
\text { processo }\end{array}$ & Sim & Sim & Sim & Não & Sim & $\mathrm{PC}$ \\
\hline & $\begin{array}{l}\text { Físicos: fragmentos } \\
\text { de madeira e metais }\end{array}$ & Sim & Sim & Sim & Não & Sim & $\mathrm{PC}$ \\
\hline \multirow[t]{3}{*}{ Fechamento } & $\begin{array}{ll}\text { Biológicos: } & \text { Esporos } \\
\text { Clostridium } & \\
\text { botulinum } & \end{array}$ & Sim & Sim & Sim & Sim & Sim & $\begin{array}{c}\mathrm{PCC}_{3} \\
(\mathrm{M})\end{array}$ \\
\hline & Químicos: Nenhum & - & - & - & - & - & - \\
\hline & $\begin{array}{l}\text { Físicos: Insetos e/ou } \\
\text { seus fragmentos }\end{array}$ & Sim & Sim & Sim & Não & Sim & PC \\
\hline
\end{tabular}


FORMULÁRIO N

$\underline{\text { RESUMO DO PLANO APPCC }}$

Nome Do PRODUTO: MEL

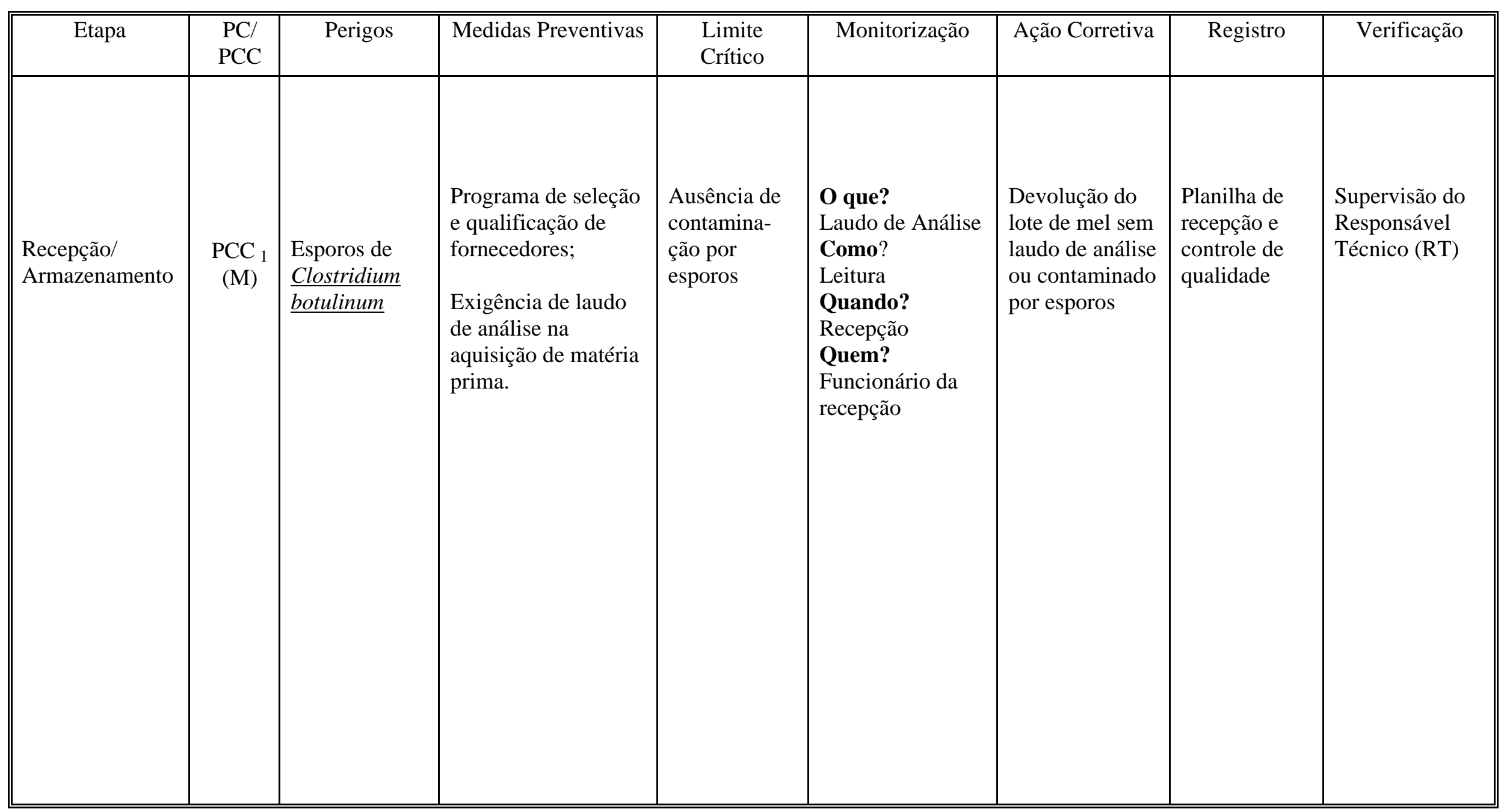


FORMULÁRIO N

RESUMO DO PLANO APPCC

NOME DO PRODUTO: MEL

\begin{tabular}{|c|c|c|c|c|c|c|c|c|}
\hline Etapa & $\begin{array}{l}\mathrm{PC} / \\
\mathrm{PCC}\end{array}$ & Perigos & Medidas Preventivas & Limite Crítico & Monitorização & Ação Corretiva & Registro & Verificação \\
\hline Descristalização & $\begin{array}{r}\mathrm{PCC}_{2} \\
(\mathrm{M}) \\
\end{array}$ & $\begin{array}{l}\text { Esporos de } \\
\text { Clostridium } \\
\underline{\text { botulinum }} \\
\\
\\
\text { Enterobactérias } \\
\text { patogênicas e } \\
\text { S.aureus }\end{array}$ & $\begin{array}{l}\text { Programa de seleção e } \\
\text { qualificação de } \\
\text { fornecedores; } \\
\text { Exigência de laudo de } \\
\text { análise na aquisição de } \\
\text { matéria prima; } \\
\\
\text { BPF'S } \\
\text { Controle de } \\
\text { portadores assintomáticos } \\
\text { Garantia de tempo e } \\
\text { temperatura adequados de } \\
\text { processamen-to } \\
\text { Controle de pH e } \\
\text { oxigênio. }\end{array}$ & $\begin{array}{l}\text { Ausência de } \\
\text { contamina- } \\
\text { ção esporos } \\
\\
\text { Ausência de } \\
\text { patógenos } \\
\text { PCMSO dos } \\
\text { manipulado-res }\end{array}$ & $\begin{array}{l}\text { O que? Laudo de } \\
\text { Análise } \\
\text { Como? Leitura } \\
\text { Quando? } \\
\text { Recepção } \\
\text { Quem? } \\
\text { Funcionário da } \\
\text { recepção } \\
\\
\text { O que? } \\
\text { Planilha de } \\
\text { Controle } \\
\text { Como? } \\
\text { Leitura } \\
\text { Quando? } \\
\text { Após } \\
\text { processamento } \\
\text { Quem? Gerente da } \\
\text { qualidade }\end{array}$ & $\begin{array}{l}\text { Devolução do lote de } \\
\text { mel sem laudo de } \\
\text { análise ou } \\
\text { contaminado por } \\
\text { esporos } \\
\\
\text { Recolhimento do } \\
\text { produto contaminado } \\
\text { e re-processa-mento, } \\
\text { se possível }\end{array}$ & $\begin{array}{l}\text { Planilha de } \\
\text { recepção e } \\
\text { controle de } \\
\text { qualidade } \\
\\
\text { Planilha de } \\
\text { controle de } \\
\text { laudos de } \\
\text { análises }\end{array}$ & $\begin{array}{l}\text { Supervisão } \\
\text { do RT }\end{array}$ \\
\hline
\end{tabular}


FORMULÁRIO N

RESUMO DO PLANO APPCC

NOME DO PRODUTO: MEL

\begin{tabular}{|c|c|c|c|c|c|c|c|c|}
\hline Fechamento & $\begin{array}{r}\mathrm{PCC}_{3} \\
(\mathrm{M})\end{array}$ & $\begin{array}{l}\text { Esporos de } \\
\text { C.botulinum } \\
\end{array}$ & $\begin{array}{l}\text { Programa de seleção } \\
\text { e qualificação de } \\
\text { fornecedores } \\
\text { Exigência de laudo } \\
\text { de análise na } \\
\text { aquisição de matéria- } \\
\text { prima }\end{array}$ & $\begin{array}{l}\text { Ausência } \\
\text { de } \\
\text { esporos }\end{array}$ & $\begin{array}{l}\text { O que? } \\
\text { Laudo de } \\
\text { análise } \\
\text { Como? } \\
\text { Leitura } \\
\text { Quando? } \\
\text { Recepção } \\
\text { Quem? } \\
\text { Funcionário } \\
\text { da recepção }\end{array}$ & $\begin{array}{l}\text { Devolução do lote } \\
\text { contaminado }\end{array}$ & $\begin{array}{l}\text { Planilha de recepção } \\
\text { e controle de } \\
\text { qualidade }\end{array}$ & Supervisão do RT \\
\hline
\end{tabular}




\section{CONCLUSÃO}

O enfoque dado ao plano foi de assegurar a inocuidade do mel, sendo considerados os perigos de natureza química, biológica e física que pudessem causar danos à saúde ou à integridade do consumidor.

A implementação do APPCC reduz a necessidade de inspeção e testes no produto final, pois o controle se dá durante todo o processamento, facilitando o cumprimento das exigências legais e permitindo o uso mais eficiente de recursos e estimulando o maior envolvimento dos manipuladores.

Confiança no fornecedor, higiene e sanificação adequadas de equipamentos, utensílios e manipuladores e atendimento às relações recomendadas de tempo/temperatura, são as principais medidas de controle para os PCCs analisados nas etapas de processamento do mel.

Os equipamentos e utensílios oferecem riscos de contaminação ao mel. Porém a adequação do processo de higienização dos equipamentos e utensílios através da conscientização dos manipuladores de alimentos por meio de treinamentos pelos responsáveis técnicos, garantem a qualidade do produto oferecido.

A disponibilização de diferentes recursos (termômetro adequado, material de limpeza e sanificação, treinamento do pessoal, e outros) que garantam controle dos principais PCCs encontrados no processo de industrialização de mel de abelhas Apis mellifera, bem como avaliação constante de todas as etapas envolvidas na implantação do sistema APPCC são importantes ferramentas para o sucesso do entreposto de mel.

A implementação do sistema APPCC na industrialização de mel de abelhas Apis mellifera certamente propiciará a obtenção de um produto final microbiologicamente seguro e com melhores características sensoriais e maior valor nutricional, aumentando, desta forma a sua aceitação por parte dos consumidores.

Há a necessidade da construção de formulários de registro que garantam a disponibilidade de dados importantes para a rastreabilidade e segurança do produto. A implantação do sistema APPCC em entrepostos de mel pode garantir a segurança do produto 
que será exposto ao consumo, desde que obedecidos os limites críticos e/ou segurança estabelecidos no referido plano APPCC. 


\section{REFERÊNCIA BIBLIOGRÁFICA}

1. ALMEIDA, C.R. O sistema HACCP como instrumento para garantir inocuidade dos alimentos. Disponível em: http://www.cvc.saude.sp.gov.br/htm/if haccp.htm. Acesso em 22/07/2002.

2. APISERVICES INTERNATIONAL HONEY MARKET. 2002. Documento on-line: http://www.apiservices.com/database/honey-market/world_honey.htm. Acesso em 18/03/2004.

3. BRASIL. Ministério da Agricultura e do Abastecimento. Regulamento Técnico para Fixação de Identidade e Qualidade de Mel. Portaria n³67 de 04 de setembro de 1997. Disponível no site: http://www.agricultura.gov.br/legislação Acesso em 01/11/2003.

4. BRASIL. Ministério da Agricultura e do Abastecimento.Portaria n.46 de 10 de janeiro de 1998. Manual genérico de procedimentos para APPCC em indústrias de produtos de origem animal. Diário Oficial da União,Brasília,1998b. Seção1.

5. CARDOSO, L.; ARAÚJO, W.M.C. "Parâmetros de qualidade em produtos prontos para consumo imediato e congelados artesanais comercializados no distrito federal no período de 1997-20001. Revista Higiene Alimentar, São Paulo, v.17, n.109, p.42-44, 2003.

6. CASTRO, M.F.P; SCHIMIDT, F.L.; LEITÃO, M.F.F. "Boas Práticas Agrícolas e Aplicação do Sistema APPPCC no cultivo e processamento industrial do café obtido pela via seca”. Revista Higiene Alimentar, São Paulo, v.16, n 96, 2002. p.29-42.

7. CRANE, Eva. O livro do mel ; tradução de Astrid Kleinert Giovannini; revisão técnica de Vera Lúcia Imperatriz Fonseca - São Paulo; Nobel, 2ª ed., 1987. 
8. EMBRAPA, Produção de mel.versão eletrônica em jan.2003. Documento on line disponível no site: http://sistemasdeproducao.cnptia.embrapa.br/ fonteshtml/ mel/spmel/comercializacao.htm acesso em 03/02/2004.

9. FARIA, J.A.F. “Embalagens e conservação de mel de abelhas”.Revista Informe Agropecuário- Sistema Estadual de Pesquisa Agropecuária: EPAMIG, ESAL, UFMG, UFV, Belo Horizonte-MG, ano 9, n.106, 1983.

10. LUCHESE, R.S; BORGES, J.T.S.; MAIA, L. M.; FREITAS, A.S. "Identificação dos Pontos Críticos de controle na preparação de carne bovina assada, em unidades de alimentação e nutrição”. Revista Higiene Alimentar, São Paulo, v.17, n 108, 2003. Pg 36-41.

11. MAKIYA, I.K.; ROTONDARO, R.G. "Integração entre os sistemas GMP/HACCP/ ISO9000 nas industrias de alimentos”. Revista Higiene Alimentar, São Paulo, v.16, $n^{\circ} 99,2002$. p.46-50.

12. NASSAU, R.T.; BENEVIDES, S.D.; BORGES, M.F.; SILVA, J.B.; ANDRADE, A. A. "Diagnóstico de Boas Práticas de Fabricação em uma indústria de polpas de frutas, visando a implantação do sistema APPCC” Revista Higiene Alimentar, São Paulo, v. 17, n 104/105, encarte, 2003, Pg131-132.

13. NOGUEIRA-NETO, , Paulo. Vida e criação de abelhas indígenas sem ferrão. São Paulo: Editora Nogueirapis, 1997. 445p.

14. OLIVEIRA, A.M.; GONÇALVES, M.O.; SHINOHARA, N.K.S.; STAMFORD, T.L.M. “Manipuladores de alimentos: um fator de risco.” Revista Higiene Alimentar, São Paulo, v.17, n.114/115, p.12-19, 2003.

15. PEREIRA, J.G.; DENADAI, J.M.; "Mel de abelhas análises de amostras comercializadas no município de Campo Grande - MS”. Revista Higiene Alimentar, São Paulo, v.2, n.4, 1983. 
16. RICHARDS, Neila S.P.S.”Segurança alimentar: como prevenir contaminações na indústria”. Revista Food Ingredients, São Paulo n 18, 2002. Pg16-26.

17. ROOT, A.I. El ABC y XYZ de la apicultura. Buenos Aires, Argentina. Ed. Hemisferio Sur S.A. 1984. 722 p. $1^{\text {a }}$ edição em espanhol

18. SENAI/DN. Elementos de apoio para o Sistema APPCC. (Série Qualidade e Segurança alimentar). Brasília, SENAI/DN, 1999. 317p. Projeto APPCC. Convênio CNI/SENAI/SEBRAE.

19. SILVA,C.; GERMANO, M.I. S.; GERMANO, P.M.L. "Conhecimentos dos manipuladores de merenda escolar em escolas da Rede Estadual de ensino em São Paulo,SP” Revista Higiene Alimentar, São Paulo, v.17, n¹13, p.46-51, 2003.

20. SILVA, C.G.M; OLIVEIRA, A.M.; STAMFORD, T.L.M. "Enteroparasitas em vegetais: uma revisão”. Revista Higiene Alimentar, São Paulo, v.17, n.109, p.13, 2003.

21. SILVA JUNIOR, E.A. Manual de Controle higiênico sanitário em alimentos. São Paulo;. Livraria Varela, $4{ }^{\mathrm{a}}$ Ed., 2001.

22. SOUZA, E.L; LIMA, E.O; NARAIN, N. "Especiarias: uma alternativa para o controle da qualidade sanitária e de vida útil de alimentos, frente às novas perspectivas da indústria alimentícia”. Revista Higiene Alimentar, São Paulo, v.17, n¹13, p.38, 2003 


\section{GLOSSÁRIO}

- Ação Corretiva- são as tomadas de ações corretivas imediatas, quando o monitoramento indicar que um critério importante não está sendo atingido.

- ANÁlise de Perigos - o processo de coleta e avaliação das informações sobre os perigos e as condições de sua procedência, para decidir quais são mais significativos para a segurança alimentar a serem destinados ao plano HACCP.

- APPCC- ou HACCP - um sistema que identifica, avalia, e indica os controles dos perigos essenciais para a segurança alimentar.

- ContaminaçÃo - é a ocorrência de qualquer material prejudicial ao produto.

- Controlar - ação de gerenciamento das condições de uma etapa ou operação, necessária para assegurar e manter o cumprimento dos critérios estabelecidos no Plano HACCP.

- Controle - condições nas quais os procedimentos operacionais foram cumpridos e os critérios plenamente atingidos.

- Controle dos Pontos críticos - são os procedimentos ou medidas de controle dos pontos críticos que possam ser tomadas para garantir a segurança do processo, objetivando a eliminação, prevenção ou redução dos perigos a níveis suportáveis.

- Desinfecção - processo através do qual, pela utilização de métodos físicos ou agentes químicos higienicamente satisfatórios e sem afetar negativamente o alimento, é reduzido o número de microrganismos a um nível que não leve à contaminação prejudicial do alimento.

- DESVio - falha ou não alcance do limite crítico.

- Diagrama de Fluxo (FluXograma) - é a seqüência ordenada das etapas ou operações usadas na produção ou preparação de um alimento que permite determinar os pontos críticos e os seus controles (PCCs).

- ESTABELECiMENTo - qualquer edifício ou área na qual o alimento é manipulado depois da colheita, assim como os ambientes contíguos que obedecem ao controle da mesma administração.

- ETAPA - um ponto, procedimento, operação ou estágio na cadeia alimentar, incluindo desde matérias-primas cruas na produção primária até o consumo. 
- Higiene Alimentar - todas as medidas necessárias para garantir a segurança, boas condições e perfeita qualidade dos alimentos em todos os estágio de seu crescimento, produção ou manufatura, até que finalmente sejam servidos ao consumidor.

- LiMite CRítico - é um valor utilizado como critério que traga segurança no controle dos pontos críticos.

- Limite Operacional - critério mais restritivo que o limite crítico indicado, usado para reduzir a probabilidade de ocorrência de desvio.

- LiMPEZA - é a remoção da sujeira, restos de alimentos, poeira, gordura ou materiais prejudiciais.

- Lote - uma quantidade determinada de um alimento, produzido essencialmente sob as mesmas condições e ao mesmo tempo.

- MANiPUlação DE ALIMENTos - qualquer preparação compreendida na produção, processamento, cozimento, armazenamento, transporte, distribuição e serviço de alimentos.

- Manipulador de alimentos - toda pessoa que manipule ou entre em contato com os alimentos ou com quaisquer equipamentos ou utensílios usados na manipulação de alimentos.

- Monitoramento - é o ato de medir ou observar se os limites críticos estão sendo respeitados para assegurar se o PCC está sob controle.

- Perigo- é a contaminação de origem biológica, química ou física em condição potencial que possa causar agravo à saúde (a sobrevivência e a multiplicação podem ser considerados perigos quando a contaminação for de origem biológica - bactérias e fungos).

- Plano hacCP - um documento preparado, de acordo com os princípios do HACCP, para assegurar os controles dos perigos, os quais são significativos para a segurança na cadeia alimentar em estudo.

- Ponto CRítico - é o local ou situação onde estão presentes os perigos com risco à saúde e que devem ser controlados. São considerados PCCs (Pontos Críticos de Controle):todos os pontos críticos onde procedimentos imediatos de controle podem ser exercidos para eliminar, prevenir ou reduzir os riscos a níveis suportáveis e que possam ser monitorados constantemente, trazendo segurança ao alimento.

- Ponto De CONTRole - é um local ou situação a ser corrigida, porém sem risco imediato à saúde. 
- Pragas - quaisquer animais(aves, insetos, roedores) capazes de contaminar direta ou indiretamente os alimentos.

- REgistro - documento específico para informações e resultados.

- Risco - é a probabilidade estimada de ocorrência dos perigos.

- SEVERIDADE - é a gravidade da doença (quadro clínico) e o grau de suas conseqüências.

- VALIDAÇão - obter evidência de que os elementos do plano HACCP são efetivos.

- VerificAÇão - a utilização, se necessário, de métodos, procedimentos, testes e outras avaliações complementares ao monitoramento, para determinar se o sistema HACCP está de acordo com o plano HACCP, ou para verificar se o plano necessita de modificação ou revalidação. 